\title{
CPAP enhances and maintains chronic inflammation in hepatocytes to promote hepatocarcinogenesis
}

\author{
Ruo-Yu Chen ${ }^{1,12}$, Chia-Jui Yen ${ }^{2,12}$, Yih-Jyh Lin $^{3}$, Ju-Ming Wang ${ }^{1}$, Ting-Fen Tasi ${ }^{4}$, Yu-Chuan Huang ${ }^{1,5}$, Yao-Wen Liu ${ }^{6}$, Hung-Wen Tsai ${ }^{7}$, \\ Ming-Hao Lee ${ }^{8}$ and Liang-Yi Hung (iD ${ }^{1,8,9,10,11^{凶}}$
}

(c) The Author(s) 2021

\begin{abstract}
Chronic and persistent inflammation is a well-known carcinogenesis promoter. Hepatocellular carcinoma (HCC) is one of the most common inflammation-associated cancers; most HCCs arise in the setting of chronic inflammation and hepatic injury. Both NF-KB and STAT3 are important regulators of inflammation. Centrosomal P4.1-associated protein (CPAP), a centrosomal protein that participates primarily in centrosome functions, is overexpressed in HCC and can increase TNF-a-mediated NF-KB activation and IL-6induced STAT3 activation. A transgenic $(\mathrm{Tg})$ mouse model with hepatocyte-specific CPAP expression was established to investigate the physiological role of CPAP in hepatocarcinogenesis. Obvious inflammatory cell accumulation and fatty change were observed in the livers of CPAP Tg mice. The alanine aminotransferase (ALT) level and the expression levels of inflammatory genes, such as IL-6, IL-1 $\beta$ and TNF- $\alpha$, were higher in CPAP Tg mice than in wild type (WT) mice. High-dose/short-term treatment with diethylnitrosamine (DEN) increased the ALT level, proinflammatory gene expression levels, and STAT3 and NF-kB activation in CPAP Tg mice; low-dose/ long-term DEN treatment induced more severe liver tumor formation in CPAP Tg mice than in WT mice. CPAP can increase the expression of chemokine (C-C motif) ligand 16 (CCL-16), an important chemotactic cytokine, in human hepatocytes. CCL-16 expression is positively correlated with CPAP and TNF- $a$ mRNA expression in the peritumoral part of HCC. In summary, these results suggest that CPAP may promote hepatocarcinogenesis through enhancing the inflammation pathway via increasing the expression of CCL-16.
\end{abstract}

Cell Death and Disease (2021)12:983; https://doi.org/10.1038/s41419-021-04295-2

\section{INTRODUCTION}

Hepatocellular carcinoma (HCC) is one of the most aggressive cancers and the second leading cause of cancer mortality worldwide [1]. Approximately $70-90 \%$ of HCC cases are associated with chronic inflammation which may result from hepatitis infection, alcoholic liver disease, or nonalcoholic fatty liver disease [2]. During liver inflammation, various types of cells interact with chemokines to prevent the spread of pathogen infection; and these interactions maintain physiological homeostasis through a negative feedback mechanism [3, 4]. However, the uncontrolled action of regulatory mechanisms resulting from sustained inflammation (e.g., macrophage polarization toward the M2 phenotype, increased immunosuppressive cell infiltration, and prolonged or excessive inflammatory responses) will cause nonresolving inflammation and subsequently lead to cellular oncogenic transformation as well as genetic and epigenetic changes [4, 5]. In addition, HCC risk factors usually lead to dysregulated production of pro- and inflammatory soluble factors from immune cells, epithelial cells and endothelial cells; therefore, HCC has been considered a typical nonresolving inflammatory disease [4]. Recently, many studies have investigated whether the regulatory relationship between various proinflammatory cells (including immune cells) and inflammatory mediators within the tumor microenvironment is a potent target for cancer prevention and therapy [6-8].

In chronic hepatitis, both hyperactivation of NF-KB and STAT3 in immune cells and hepatocyte injury contribute to the production of pro- and inflammatory factors that maintain a protumor microenvironment in the liver [9]. Although making a definitive diagnosis of liver cancer by hyperactivation of NF-KB and STAT3 is difficult, to date, the efficacy of several developed drugs targeting specific cytokines, such as IL-6, to inhibit NF-KB and STAT3 hyperactivation has been evaluated in phase I and phase II clinical trials in various cancer types [10-12].

Chemokine (C-C motif) ligand 16 (CCL-16), also called liverexpressed chemokine (LEC), is strongly expressed by liver

\footnotetext{
${ }^{1}$ Department of Biotechnology and Bioindustry Sciences, College of Bioscience and Biotechnology, National Cheng Kung University, Tainan, Taiwan. ${ }^{2}$ Department of Oncology, Tainan, Taiwan. ${ }^{3}$ Department of Surgery, National Cheng Kung University Hospital, College of Medicine, National Cheng Kung University, Tainan, Taiwan. ${ }^{4}$ Department of Life Sciences and Institute of Genome Sciences, National Yang Ming Chiao Tung University, Taipei, Taiwan. ${ }^{5}$ Genomics Research Center, Academia Sinica, Taipei, Taiwan. ${ }^{6}$ Department of Clinical Pathology, Kuo General Hospital, Tainan, Taiwan. ${ }^{7}$ Department of Pathology, National Cheng Kung University Hospital, College of Medicine, National Cheng Kung University, Tainan, Taiwan. ${ }^{8}$ Department of Pharmacology, College of Medicine, National Cheng Kung University, Tainan, Taiwan. ${ }^{9}$ Institute for Cancer Biology and Drug Discovery, College of Medical Science and Technology, Taipei Medical University, Taipei, Taiwan. ${ }^{10}$ Graduate Institute of Medicine, College of Medicine, Kaohsiung Medical University,

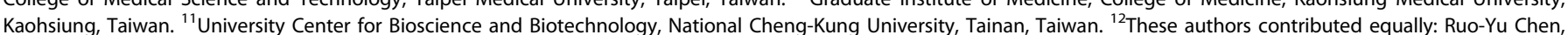
Chia-Jui Yen. ${ }^{凶}$ email: lyhung@mail.ncku.edu.tw

Edited by Dr. Angelo Peschiaroli
}

Received: 7 June 2021 Revised: 4 October 2021 Accepted: 8 October 2021

Published online: 22 October 2021 
(A)

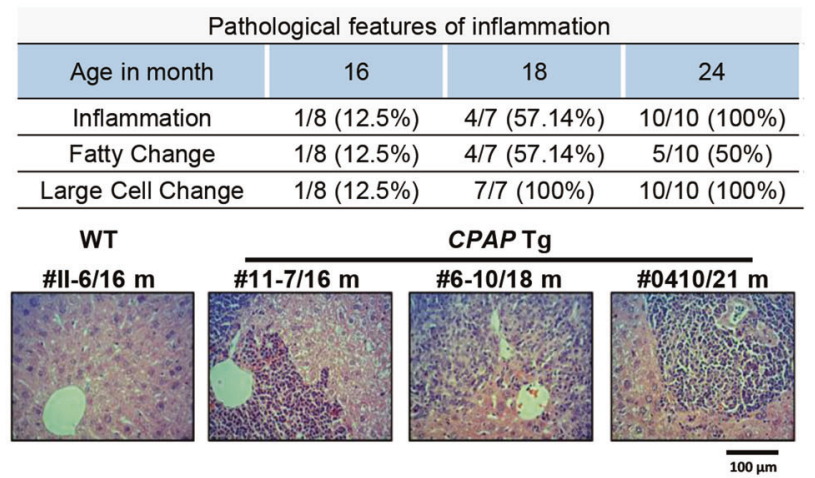

(C)

\begin{tabular}{|c|c|c|c|c|}
\hline $\begin{array}{l}\text { Age in } \\
\text { month }\end{array}$ & & 16 & $17-18$ & $19-21$ \\
\hline WT & ALT & $1 / 7(14.3 \%)$ & $3 / 14(21.4 \%)$ & $4 / 18(22 \%)$ \\
\hline $\begin{array}{c}\text { CPAP } \\
\mathrm{Tg}\end{array}$ & $>50 \mathrm{U} / \mathrm{L}$ & $6 / 30(20 \%)$ & $18 / 47(38.3 \%)$ & 11/26 (42.3\%) \\
\hline
\end{tabular}

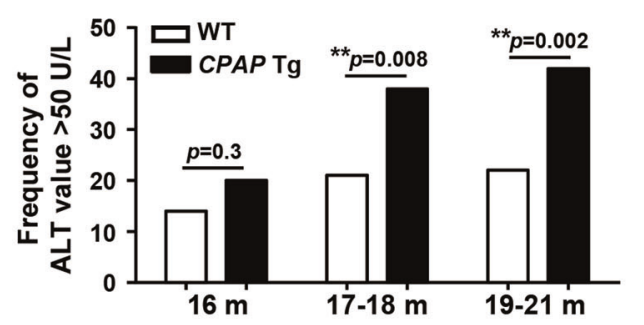

(E)

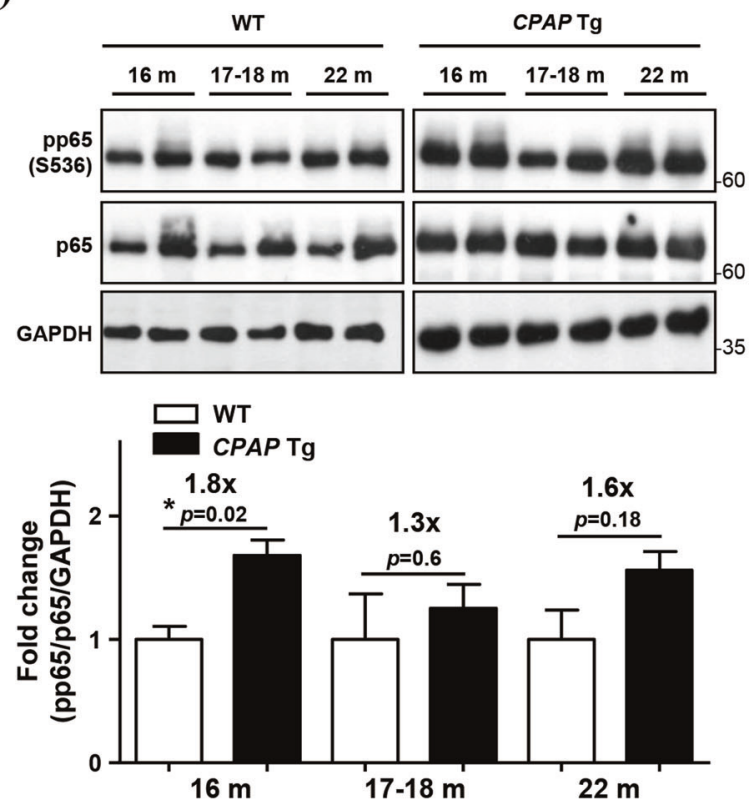

parenchymal cells and also expressed by the thymus and spleen $[13,14]$. Biological functions of CCL-16 have been demonstrated to be involved in the immune response and chemotaxis by binding with CCR1, CCR2, CCR5 and CCR8 [14-17]. Several lines of evidence have indicated that CCL-16 plays an important role in immune responses as well as inflammatory activity. CCL-16 can
(B)

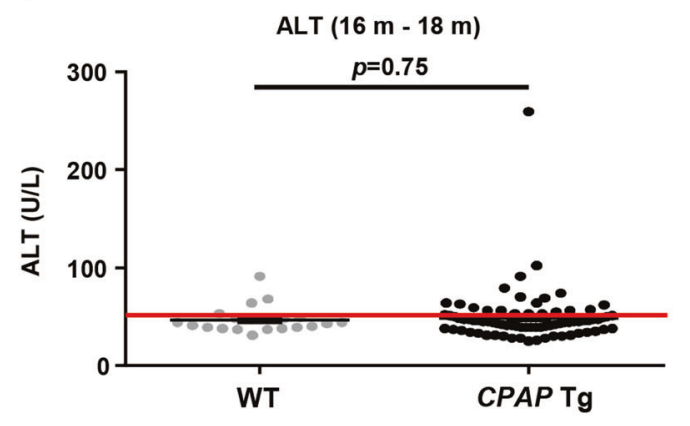

(D)
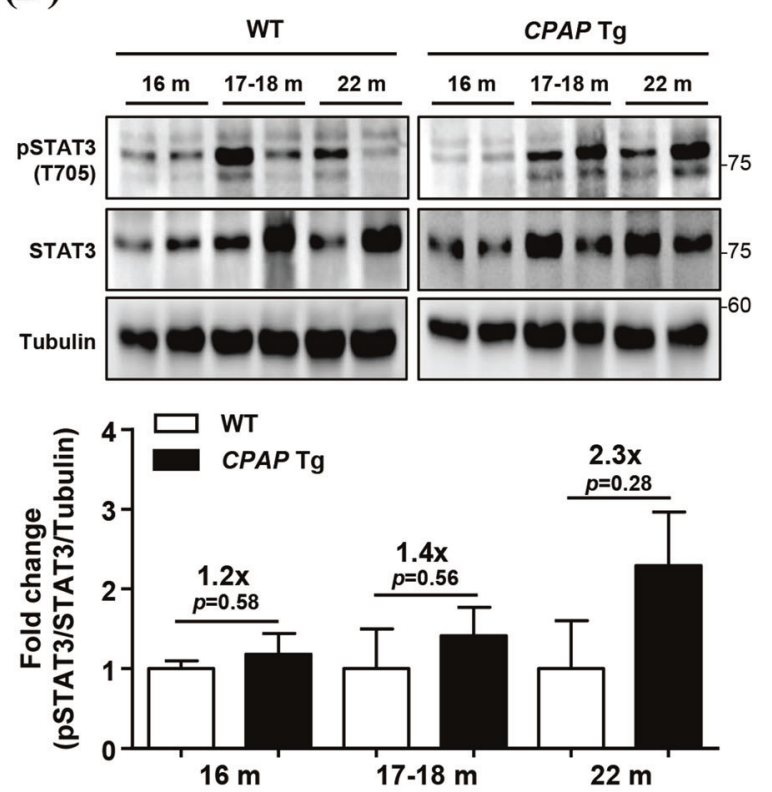

(F)
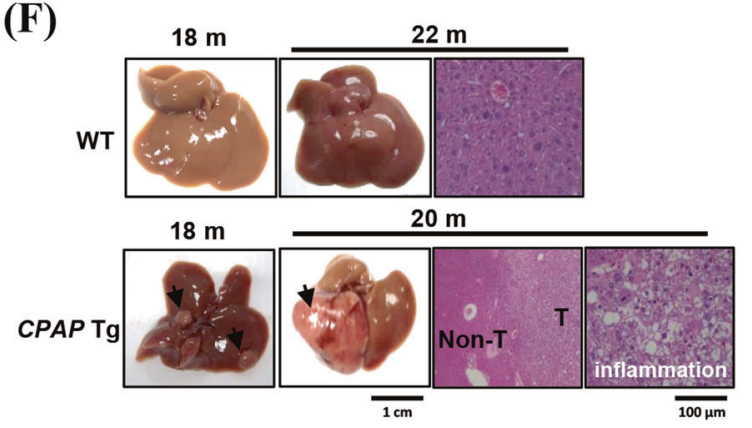

\begin{tabular}{cccc}
\multicolumn{4}{c}{ Number of bred mice developing HCCs per month interval } \\
\hline Age in month & $17-18$ & $19-20$ & $21-24$ \\
\hline WT & - & $0 / 4(0 \%)$ & $0 / 4(0 \%)$ \\
\hline CPAP Tg & $1 / 14(7.1 \%)$ & $2 / 11(18.2 \%)$ & $1 / 28(3.6 \%)$ \\
\hline
\end{tabular}

drive the chemotaxis of monocytes, lymphocytes, eosinophils and dendritic cells; [18-20] CCL-16 and IL-10 can cooperatively enhance monocyte infiltration [21]. Importantly, CCL-16 can increase the effector and antigen-presenting functions of macrophages and augment T cell cytotoxicity [22]. High levels of CCL-16 in serum and plasma are closely correlated with inflammation- 
Fig. 1 CPAP Tg mice display inflammatory features and promotion of hepatic tumorigenesis. A (Upper) The histopathological features of inflammation, including inflammatory cell infiltration, fatty changes and large cell change, in CPAP Tg and WT mice of various ages. (Lower) Liver tissues of CPAP Tg and WT mice were collected for H\&E staining. Four representative liver tissues from one 16-month-old WT (\#11-6/ $16 \mathrm{~m})$ and three CPAP Tg (\#11-7/16 m, \#6-10/18 m, and \#0410/21 m) are shown. B Serum ALT levels in CPAP Tg mice $(n=77)$ and WT mice $(n=$ 21) aged 16 months $(16 \mathrm{~m})$ to 18 months $(18 \mathrm{~m})$ were measured with a FUJIFILM DRI-CHEM 4000i chemistry analyzer. Quantitative results are shown as the mean \pm SEM values. Student's t test, $p=0.75$. C Percentages of CPAP Tg and WT mice with a serum ALT level higher than 50 U/L. The quantitative results of the frequency of ALT $>50 \mathrm{U} / \mathrm{L}$ were analyzed by chi-square test. ${ }^{* *} p<0.01$. D, E Total lysates of liver tissues from WT and CPAP Tg mice with different ages were collected for WB analysis using the indicated antibodies. Livers were collected form two mice of each age for analysis. Tubulin and GAPDH were used as loading controls. Quantitative results of the WB analysis are shown below. F Representative images of gross liver tumors and H\&E-stained sections from WT and CPAP Tg mice of different ages are shown. Inflammation, tumor ( $\mathrm{T}$ ) tissues and nontumor (Non-T) tissues are shown. The incidence rates of liver tumors in WT and CPAP Tg mice from 17 to 24 months of age are listed in the table.

related diseases, such as irritable bowel syndrome (IBS) and ulcerative colitis (UC) [23-25]. CCL-16 can regulate angiogenesis by interacting with CCR1 in endothelial cells; and the restricted expression of CCL-16 in liver cells may therefore contribute to hepatic vasculogenesis during hepatocarcinogenesis [26]. However, the role and regulatory mechanism of CCL-16 in HCC remain unclear.

Centrosomal P4.1-associated protein (CPAP) is a component of the $\gamma$-tubulin complex and participates in centrosome-related functions $[27,28]$. Our previous studies demonstrated that CPAP is required for the activation of TNF-a-mediated NF-KB and IL-6mediated STAT3 signaling in HCC [29-31]. SUMO-1-modified CPAP enhances the transcriptional activity of NF-KB in HCC cells [31]; overexpressed CPAP directly interacts with STAT3 to enhance IL-6mediated STAT3 activation and promote HCC tumor growth and metastasis [29]. However, the underlying mechanisms and crosstalk between CPAP and chronic inflammation in the liver are still unclear. Here, we observed several pathological features of inflammation in transgenic (Tg) mice with liver-specific CPAP overexpression. In a model of diethylnitrosamine (DEN)-induced hepatic injury in CPAP Tg mice, ALT levels, apoptosis, and the tumor number and size were increased. In hepatocytes, SUMO-1 modification maintained CPAP protein stability upon IL- 6 or TNF-a stimulation. SUMOylated CPAP and TNF-a form an inflammatory feedback loop to accelerate hepatocarcinogenesis. Furthermore, CPAP overexpression promoted proinflammatory cell infiltration through TNF-a/CCL-16 signaling. Our studies provide evidence for the critical role of CPAP in inflammation-mediated hepatocarcinogenesis, and CPAP-mediated upregulation of CCL-16 can be a serum biomarker for early diagnosis of premalignant lesions of HCC.

\section{RESULTS}

Hepatocyte overexpressed CPAP promotes chronic inflammation and induces HCC tumorigenesis

CPAP was reported to be an essential factor for TNF-a-mediated NF-KB and IL-6-mediated STAT3 activation in HCC [29-31]. Upon $\mathrm{HBV}$ infection, the viral oncoprotein $\mathrm{HBx}$ transcriptionally increases the expression of CPAP to enhance HCC development [30]. To evaluate the effects of CPAP in hepatocarcinogenesis, we assessed the physiological roles of overexpressed CPAP in hepatocytes. We generated $\mathrm{Tg}$ mice expressing human CPAP under the control of the human albumin promoter with two copies of chicken $\beta$-globin 5'HS4 as insulators (for details, please see the Materials and Methods section). Founder mice were generated by injecting the albumin-driven CPAP construct into fertilized eggs of C57BL/6 mice (Supplementary Fig. S1A); three lines of liver-specific CPAP $\mathrm{Tg}$ mice were selected for further investigation. Genotyping of CPAP Tg mice was performed by PCR (Supplementary Fig. S1B), and CPAP Tg mice were phenotypically similar to wild type (WT) mice. At 16 months of age, pathological features of inflammation, including inflammatory cell infiltration, fatty changes and liver cell dysplasia (large cell change), appeared in the livers of CPAP Tg mice. Inflammatory cell infiltration and liver cell dysplasia, appeared in all CPAP $\mathrm{Tg}$ mice (10/10) at 24 months of age (Fig. 1A). The serum ALT levels did not differ significantly between WT and CPAP Tg mice aged 16 months to 18 months (Fig. 1B). We analyzed the serum ALT level in mice at different ages and found that the percentage of mice with a serum ALT level $>50 \mathrm{U} / \mathrm{L}$ was higher in the CPAP Tg groups than in the WT groups aged 17 months to 18 months and 19 months to 21 months (Fig. 1C and Supplementary Fig. S2). Increased NF$\kappa B$ and STAT3 activity was observed in the livers of CPAP Tg mice aged 16 months to 22 months (Fig. 1D, E). Importantly, a certain percentage of CPAP Tg mice exhibited HCC from approximately 17 months of age (Fig. 1F). These results suggested that hepatic overexpression of CPAP may cause HCC formation via the sustained chronic inflammation.

\section{CPAP overexpression enhances DEN-induced inflammation and liver tumor growth}

Previous reports indicated that the pathologic and genetic alterations seen in DEN-induced carcinogenic hepatic injury are similar to those seen in human $\operatorname{HCC}[32,33]$. To further investigate the effects of CPAP on inflammation-induced HCC formation, CPAP Tg mice were treated with DEN to induce hepatic injury and hepatocarcinogenesis. High-dose/short-term and low-dose/long-term DEN treatments were administered to CPAP Tg and WT mice (Figs. $2 \mathrm{~A}$ and $3 \mathrm{~A}$ ). After $24 \mathrm{~h}$ and $48 \mathrm{~h}$ of high-dose DEN $(100 \mathrm{mg} / \mathrm{kg})$ treatment, the serum ALT level in CPAP Tg mice was higher than that in WT mice (Fig. 2B). Nonresolving inflammation has been reported to increase DNA damage and cytokine-induced compensatory cell proliferation, both of which promote tumor growth [4]. The liver tissues of high-dose DEN-treated CPAP Tg mice showed increased levels of cleaved-caspase 3 protein and $I L-1 \beta, I L-6$ and TNF- $\alpha$ mRNAs (Fig. 2C, D), as well as increased activation of STAT3 and NF-KB (Fig. 2E, F). For the low-dose/long-term DEN treatment (Fig. 3A), we found that a poor survival rate was observed in CPAP Tg mice treated with $50 \mathrm{mg} / \mathrm{kg}$ DEN (Fig. 3B). In order to determine the effect of CPAP in liver tissues within a chronic inflammatory environment, CPAP Tg and WT mice were treated with a lower dosage of DEN (25 mg/kg) for 9-11 months. The results showed that low-dose DEN $(25 \mathrm{mg} / \mathrm{kg})$ treatment resulted in a higher tumor volume and number of tumor nodules in CPAP Tg mice than WT mice mice (Fig. 3C). As expected, activation of STAT3 and NF-KB was increased in livers of those low-dose and longterm DEN-treated CPAP Tg mice (Fig. 3D, E). These results suggested that overexpression of CPAP enhances inflammationinduced hepatocarcinogenesis through increased activation of STAT3 and NF-KB.

Previous studies reported that HBV-induced chronic liver inflammation is considered a major causative factor of hepatocarcinogenesis [4, 34]. CPAP increases HBx protein stability in an NF-KB-dependent manner, and facilitates HCC growth and progression [30]. To further investigate the ability of overexpressed CPAP in inflammation-induced hepatocarcinogenesis, 
(A)

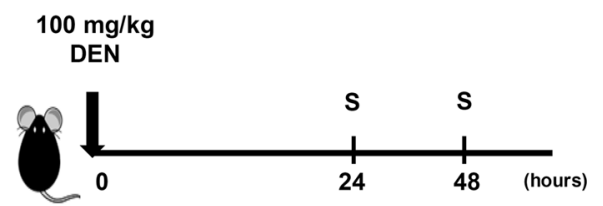

(C)

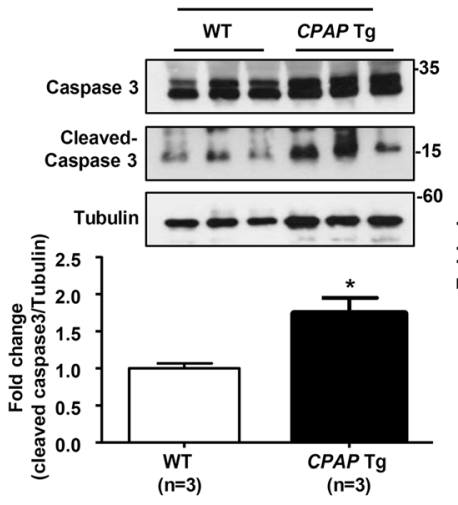

(D)
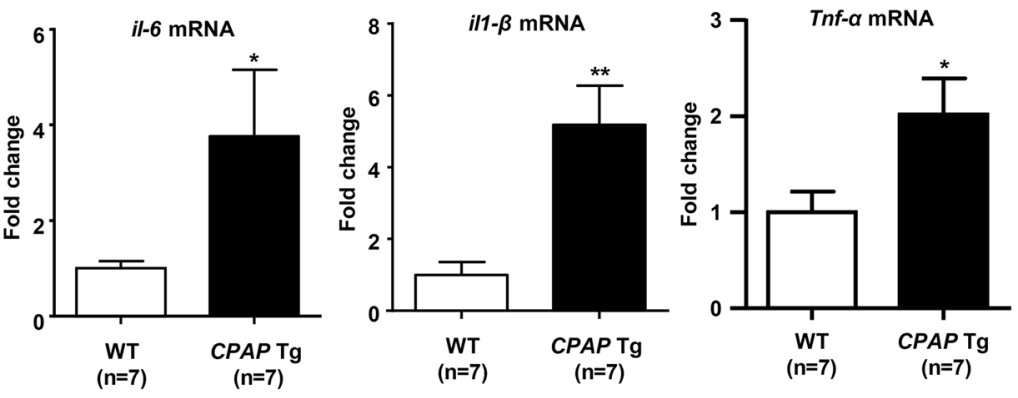

(E)

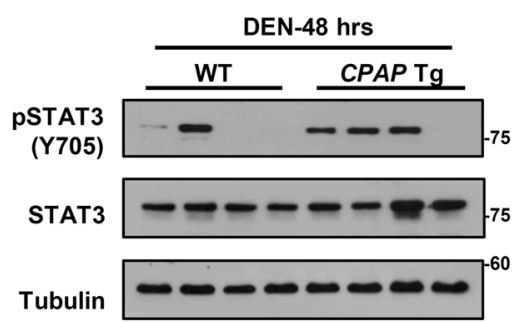

PSTAT3

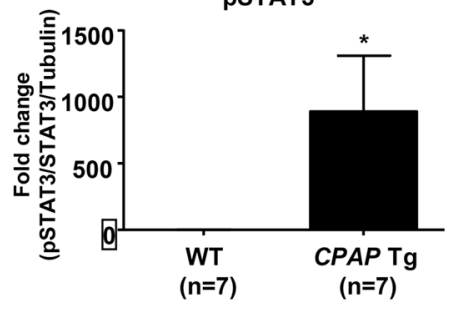

48 hrs after DEN injection

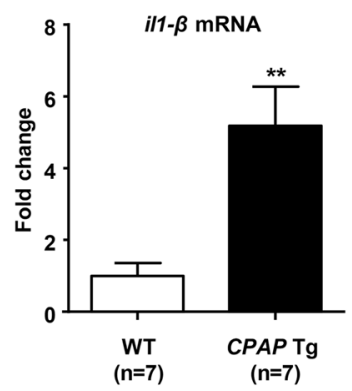

(B)

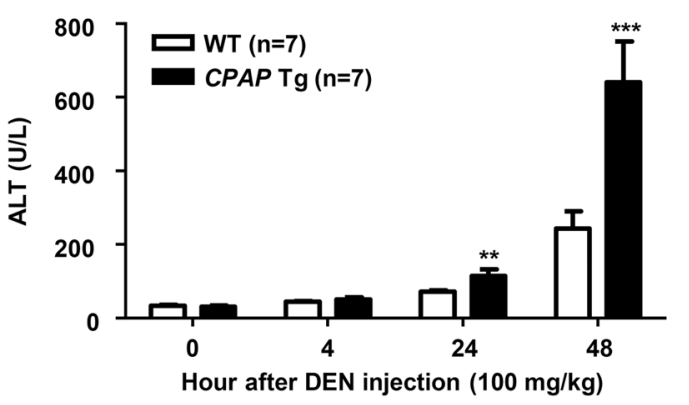

(F)

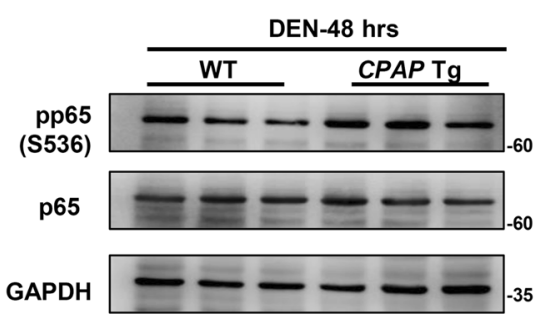

pp65

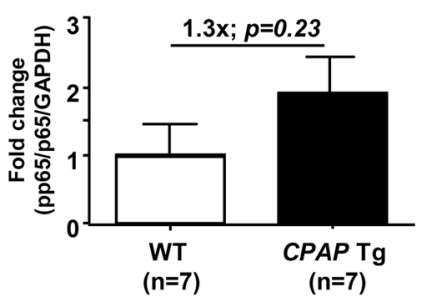

$48 \mathrm{hrs}$ after DEN injection

Fig. 2 CPAP enhances DEN-induced inflammation and liver damage. A Schematic diagram of the protocol for high-dose DEN treatment in CPAP Tg and WT mice. Two-month-old male mice were injected IP with $100 \mathrm{mg} / \mathrm{kg}$ DEN (arrow). At $24 \mathrm{~h}$ and $48 \mathrm{~h}$, mice were sacrificed (S), and liver tissue was collected for analysis. B The serum ALT levels in CPAP Tg mice $(n=7)$ and WT mice $(n=7)$ were measured $0,4,24$ and $48 \mathrm{~h}$ after DEN injection. C Forty-eight hours after DEN treatment, liver tissues were collected from CPAP Tg and WT mice to assess apoptosis by WB analysis using anti-caspase 3 and anti-cleaved caspase 3 antibodies. Quantitative results are shown below. Tubulin was used as the loading control. D RT-qPCR analysis of proinflammatory factor expression levels in the liver tissues of CPAP Tg and WT mice $48 \mathrm{~h}$ after DEN injection. The data are presented as the mean \pm SEM values. ${ }^{*} p<0.05,{ }^{* *} p<0.01$. E, F Activation of STAT3 and NF-KB in the livers of DEN-treated mice was evaluated by WB analysis using anti-phospho-STAT3/Y705 (E) and anti-phosph-p65/S536 antibodies (F). WB analysis was performed on liver tissues from three representative CPAP Tg and WT mice, and quantitative results from seven mouse livers are shown below. Tubulin and GAPDH were used as loading controls.

we generated $\mathrm{CH}$ Tg mice. Liver tumors were observed in $100 \%$ (7/7) of $\mathrm{CH}$ Tg mice between 10 and 14 months of age, and only $60 \%(6 / 10)$ of $H B x \mathrm{Tg}$ at that same age (Supplementary Fig. S3). These results confirmed that CPAP overexpression enhances chronic inflammation-mediated hepatocarcinogenesis.

\section{SUMO-1 modification maintains CPAP protein stability}

Our results suggested that CPAP plays an important role in liver inflammation (Figs. 1D, E, 2E, F and 3D, E; $[29,31]$ ). Here, we evaluated the expression level of CPAP mRNA in the livers of DENtreated mice. The results showed that CPAP mRNA was increased 
(A)

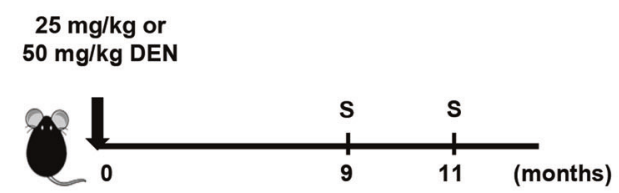

(B)

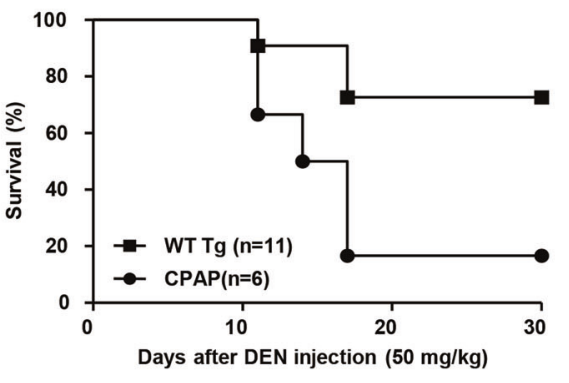

hazard ratio $7.729 ; 95 \% \mathrm{Cl}: 1.418$ to 42.13 , ${ }^{*} P=0.018$, log-rank test

(C)

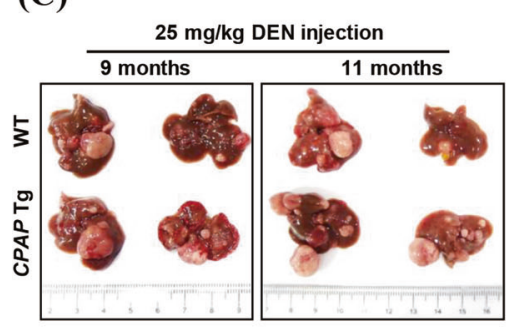

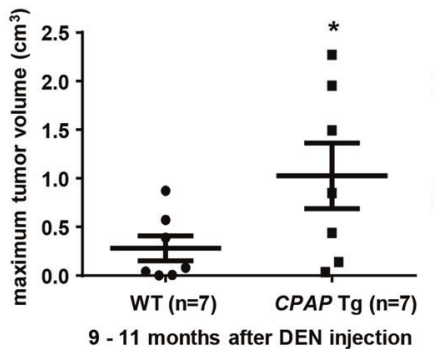

(25 $\mathrm{mg} / \mathrm{kg}$ )

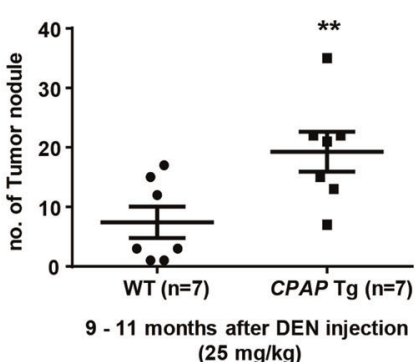

(25 mg/kg)
(D)
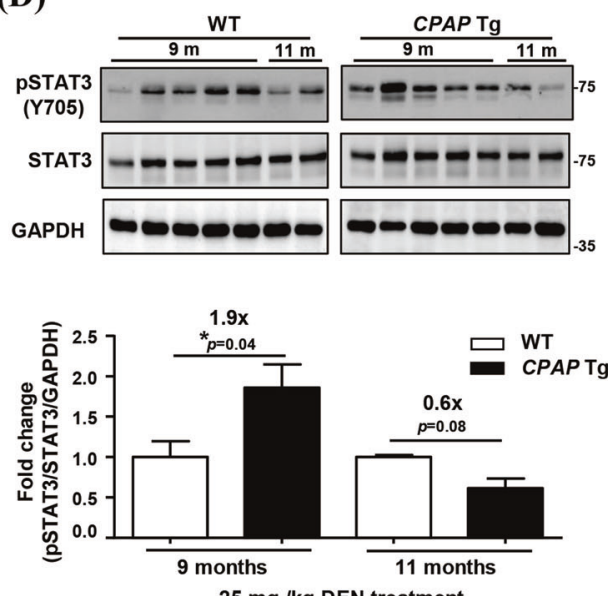

$25 \mathrm{mg} / \mathrm{kg}$ DEN treatment
(E)
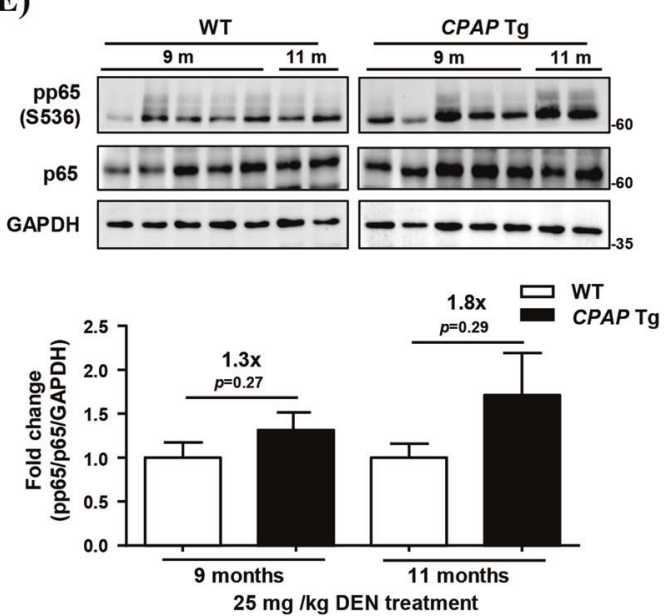

Fig. 3 CPAP enhances DEN-induced hepatic tumorigenesis. A Schematic illustration of the protocol for low-dose DEN (25 mg/kg or $50 \mathrm{mg} /$ $\mathrm{kg}$ ) treatment in CPAP Tg and WT mice (arrow). Mice were sacrificed 9 and 11 months after DEN injection $(\mathrm{S})$. B Survival rate of CPAP Tg $(n=6)$ and WT mice $(n=11)$ after $50 \mathrm{mg} / \mathrm{kg}$ DEN injection. Statistical analysis was performed using the log-rank test (Mantel-Cox method). HR = 7.729; $95 \%$ Cl: 1.418 to $42.13, p=0.018$. C Representative gross images of liver tumors in WT and CPAP Tg mice 9 and 11 months after 25 mg/ $\mathrm{kg} \mathrm{DEN} \mathrm{injection} \mathrm{are} \mathrm{shown} \mathrm{(left);} \mathrm{the} \mathrm{tumor} \mathrm{volume} \mathrm{(middle)} \mathrm{and} \mathrm{nodule} \mathrm{number} \mathrm{(left)} \mathrm{were} \mathrm{determined.} \mathrm{D,} \mathrm{E} \mathrm{Activation} \mathrm{of} \mathrm{STAT3} \mathrm{(D)} \mathrm{and} \mathrm{NF-}$ $\kappa \mathrm{B}(\mathbf{E})$ in liver tissues of DEN-treated mice was evaluated as described in the legend for Fig. 2E, F. GAPDH was used as the loading control, and the quantitative results are shown. ${ }^{*} p<0.05$.

in the livers of DEN-treated WT mice (Fig. 4A). Since DEN treatment results in enhanced hepatic inflammation $(2 \mathrm{E}-2 \mathrm{~F}$, and $3 \mathrm{D}-3 \mathrm{E})$, we speculated that the increased transcription of CPAP may be due to hyperactivated STAT3 and NF-KB signaling in the livers of DEN-treated mice. To investigate this possibility, we measured the expression level of CPAP in hepatocytes under IL-6 or TNFa treatment. Unexpectedly, only the protein expression level, not the mRNA expression level, of CPAP was increased in human hepatocytes upon IL-6 or TNF-a stimulation (Fig. 4B). The protein expression of CPAP gradually increased with cytokine treatment (Fig. 4C), but the CPAP mRNA level did not change (Supplementary Fig. S4).
The literature indicates that SUMO-1 modification plays a crucial role in hepatitis virus replication and is also associated with inflammatory liver diseases and HCC development [35-37]. In addition, our previous report indicated that CPAP can be SUMO-1 modified upon cytokine stimulation [31]. Therefore, we investigated CPAP protein stability under IL- 6 or TNF-a treatment. The results indicated that CPAP protein stability was increased in hepatocytes upon IL-6 or TNF-a treatment (Fig. 4D), and the in situ PLA results indicated that CPAP is SUMO-1 modified in hepatocytes after the addition of IL-6 or TNF-a (Fig. 4E). In contrast, the level of SUMO-1-deficient CPAP [31] was not increased in hepatocytes upon IL-6 or TNF-a treatment (Fig. 4F). 
(A)

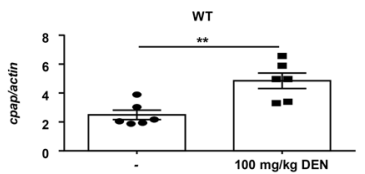

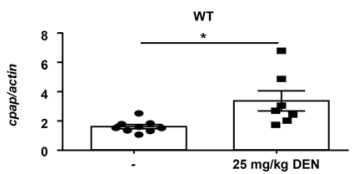

(C)
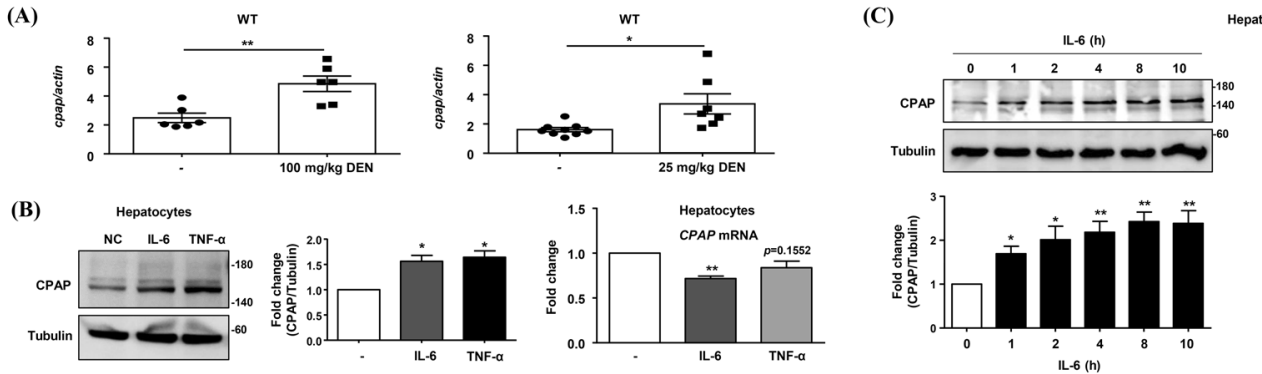

(F)

(E)

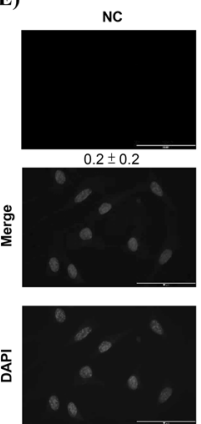

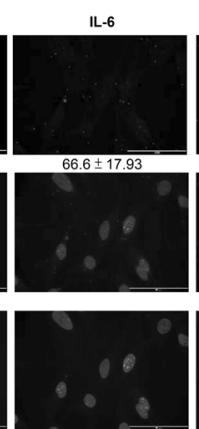
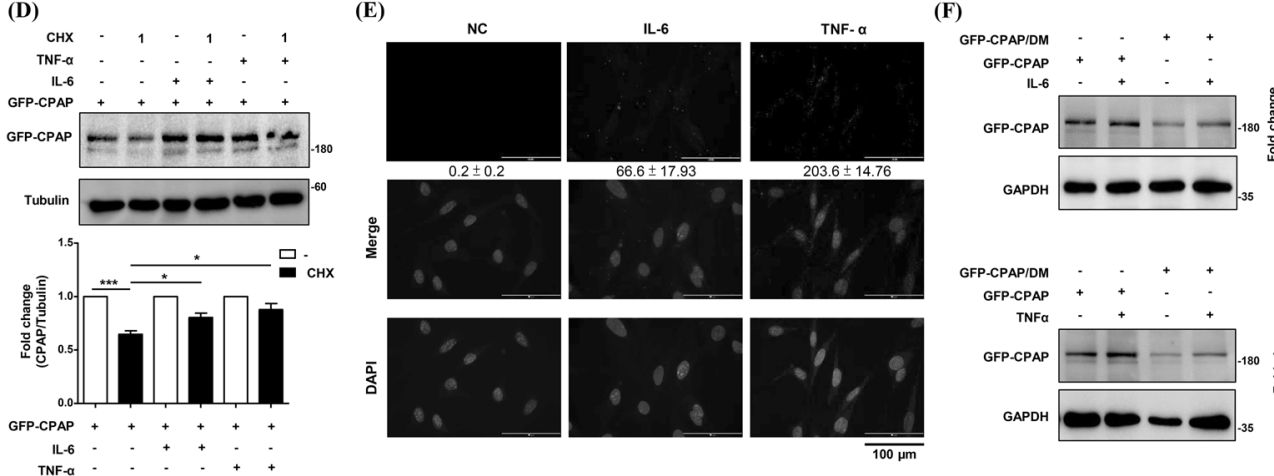

$\overline{100 \mu \mathrm{m}}$
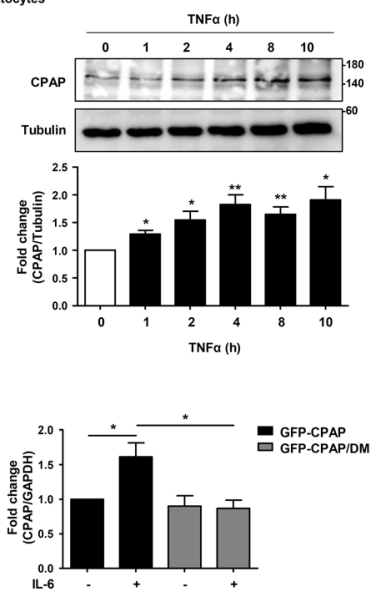

TNF $\alpha(h)$

Fig. 4 Treatment with either IL-6 or TNF-a maintains CPAP protein stability via SUMO-1 modification. A Expression levels of cpap mRNA in liver tissues from WT mice treated with $100 \mathrm{mg} / \mathrm{kg}$ DEN (left, $n=6$ ) for $48 \mathrm{~h}$ and with $25 \mathrm{mg} / \mathrm{kg}$ DEN (left, $n=7$ ) for $11 \mathrm{months}$ were determined by RT-qPCR and normalized to actin mRNA. Liver tissues from untreated mice (-) were used as the negative control. B Human hepatocytes treated with $25 \mathrm{ng} / \mathrm{ml} \mathrm{IL-6}$ or $10 \mathrm{ng} / \mathrm{ml} \mathrm{TNF-} \alpha$ for $24 \mathrm{~h}$ were collected for WB analysis (left) and RT-qPCR (right). Tubulin was used as the loading control for WB analysis; the expression level of CPAP mRNA was normalized by actin mRNA. C Human hepatocytes were treated with $25 \mathrm{ng} / \mathrm{ml} \mathrm{IL-6}$ (upper) or $10 \mathrm{ng} / \mathrm{ml}$ TNF- $\alpha$ (lower) for the indicated time periods. Total cell lysates were collected and subjected to WB analysis. Tubulin was used as the loading control. The quantitative results are shown. D Human hepatocytes were transiently transfected with GFP-CPAP and treated with $25 \mathrm{ng} / \mathrm{ml} \mathrm{IL-6}$ or $10 \mathrm{ng} / \mathrm{ml}$ TNF- $\alpha$ for $4 \mathrm{~h}$ and then with $200 \mu \mathrm{g} / \mathrm{ml}$ cycloheximide (CHX) for an additional $1 \mathrm{~h}$. Total cell lysates were collected for WB analysis using anti-GFP antibodies. Tubulin was used as the loading control. The quantitative results are shown. E In situ PLA was performed in IL- 6 or TNF- $\alpha$-treated human hepatocytes using anti-CPAP and anti-SUMO-1 antibodies. PLA signals were detected by fluorescence microscopy as distinct bright red puncta at 400X magnification. F Human hepatocytes transfected with GFPCPAP or GFP-CPAP SUMO-deficient mutant (GFP-CPAP/DM) were treated with (+) or without (-) TNF- $\alpha$ (left) or IL-6 (right) for $8 \mathrm{~h}$. Total cell lysates were collected and subjected to WB analysis using anti-GFP antibodies. GAPDH was used as the loading control. The quantitative results are shown.

These results suggested that SUMO-1 modification increases CPAP protein stability in chronically inflamed hepatocytes.

\section{CPAP maintains the inflammatory status in HCC-adjacent normal tissues (NT) by increasing STAT3 and NF-KB activity} To investigate the regulatory mechanism underlying CPAPmediated enhancement of liver inflammation, reporter assay and WB analysis were performed to assess the activation of STAT3 and NF-kB in GFP-CPAP-overexpressing and CPAP-knock down hepatocytes. As shown in Fig. 5A, B, ectopic expression of CPAP increased the phosphorylation and transcriptional activity of STAT3 and NF-KB (Fig. 5A, B), whereas knockdown of CPAP inhibited the phosphorylation of STAT3 and NF-KB in hepatocytes (Fig. 5C). HACPAP overexpression increased TNF- $a$ and $I L-8$ gene expression (Fig. 5D); in contrast, knockdown of CPAP decreased TNF- $a$ and IL-8 expression (Fig. 5E). The association between CPAP and liver inflammation was evaluated in the NCKUH cohort (Supplementary Table 1) and The Cancer Genome Altas-Liver Hepatocellular Carcinoma (TCGA-LIHC) dataset (Supplementary Tables 2 and 3) using the lymphocytic infiltration level (Supplementary Table 3) and Ishak staging system (Supplementary Tables 1 and 2), which is widely used to assess the stages of liver fibrosis [38]. Interestingly, the expression of CPAP mRNA and TNF- $a$ mRNA in HCC-adjacent normal tissues (NTs) was positively correlated with an increased inflammatory status (with mild and severe lymphocyte infiltration) (Fig. 5F, G), but was not correlated with the Ishak fibrosis scores (Fig. 5H, I, Supplementary Fig. S5). CPAP mRNA expression is positively correlated with TNF- $a$ mRNA expression in HCC adjacent normal tissues (NTs) with mild and severe grades of lymphocytic infiltration (Fig. 5J, K). These results suggested that CPAP can induce chronic inflammation in the liver by increasing lymphocytic infiltration, which leads to hepatocarcinogenesis.

\section{Liver-secreted CCL-16 is a potential biomarker for chronic inflammation}

In 2019, Andras Franko et al., proposed a secretome profile in primary human hepatocytes (PHHs) and HepG2 HCC cells via liquid chromatography with tandem mass spectrometry (LC-MS/ MS) analysis [39]. A total of 691 and 745 secreted proteins were identified in PHHs and HepG2 cells, respectively. After performing a pathway enrichment analysis with g:Profiler (https://biit.cs.ut.ee/ gprofiler), several HCC-specific expressed proteins were identified and further filtered by analysis of the Human Protein Atlas (https:// www.proteinatlas.org/) (Supplementary Fig. S6). Three liverspecific secreted proteins potentially involved in the inflammatory response were identified: prothrombin $(F 2)$, which is highly expressed in HepG2 cells (HepG2 riBAQ [\%] / PHH riBAQ [\%] = 4.2); mannose binding lectin 2 (MBL2), which has a low expression level in HepG2 cells (HepG2 riBAQ [\%] / PHH riBAQ [\%] = 0.034); and CCL-16, which is expressed only in HepG2 cells (Supplementary Fig. S6). We first analyzed the expression of these three genes in the TCGA-LIHC dataset; surprisingly, we did not find overexpression of CCL-16, MBL2, or F2 mRNAs in HCC tumor tissues (Supplementary Fig. S7). 
(A)

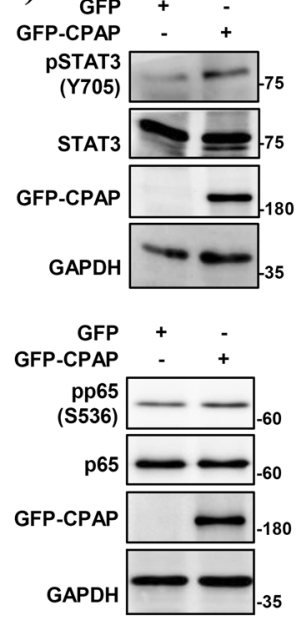

(B)

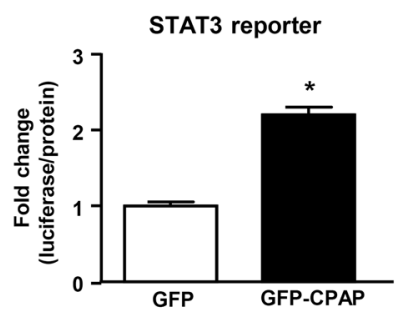

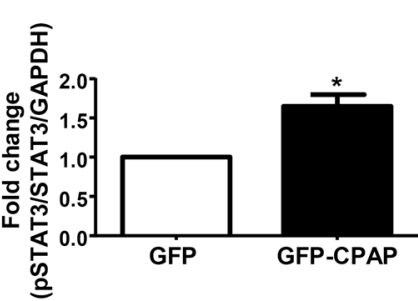

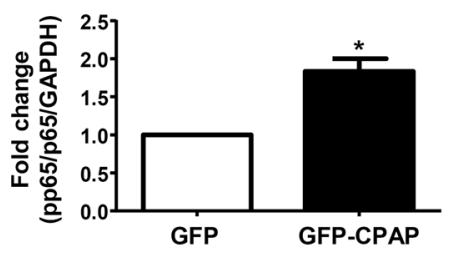

(C)
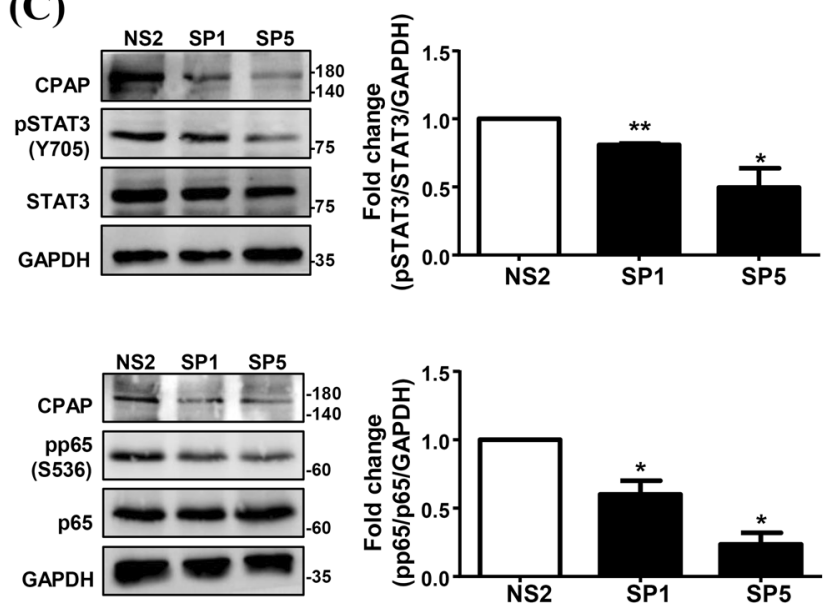

(E)
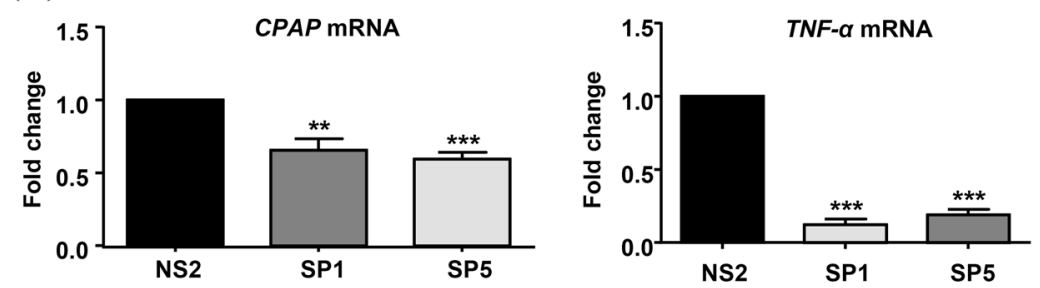

(F)

(G)

(D)
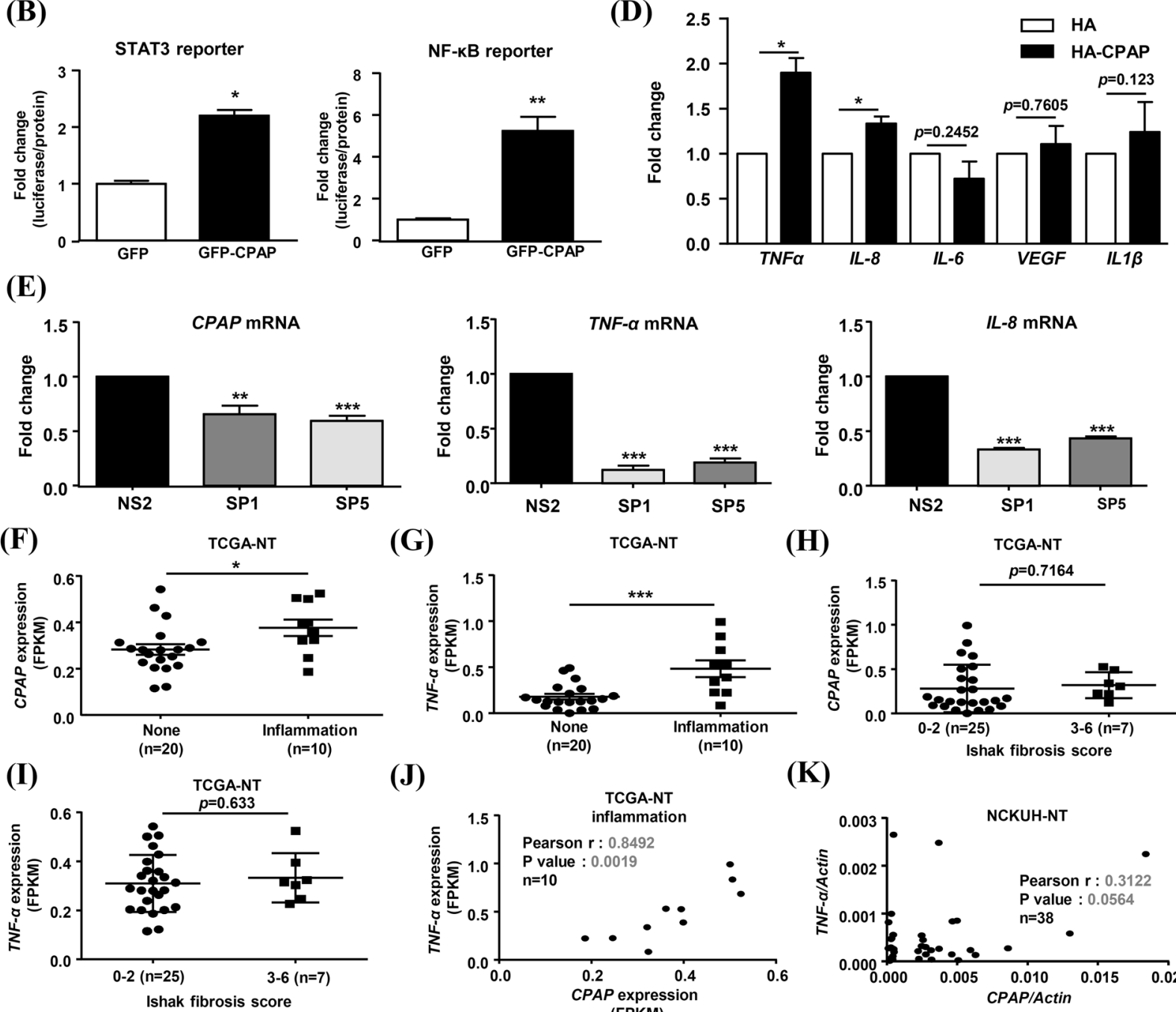

(J)
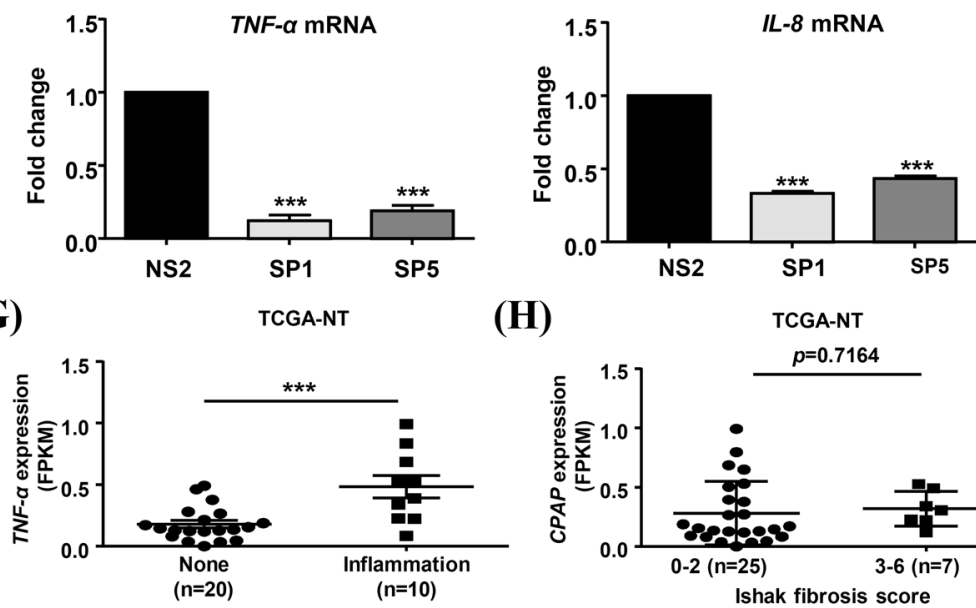

(H)

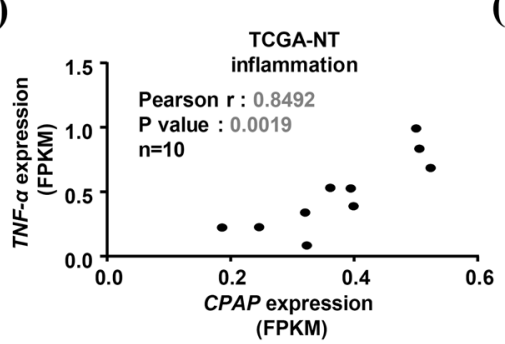

(K)

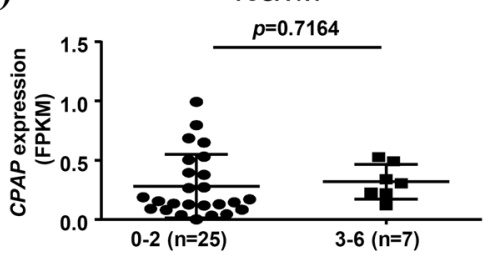

Ishak fibrosis score

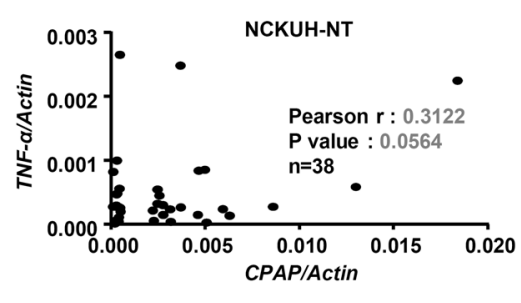

We confirmed whether the expression of these liver-enriched genes is regulated by inflammatory signaling pathways in IL-6- or TNF-a-treated human hepatocytes. CCL-16 and MBL2 mRNA levels were increased in IL-6- or TNF-a-treated hepatocytes (Fig. 6A, B), and the F2 mRNA level was slightly increased upon IL-6- or TNF-atreatment (Fig. 6C). Moreover, the expression of CCL-16, MBL2, and
F2 mRNA weas not correlated with the Ishak fibrosis score in HCCadjacent normal tissues (Fig. 6D-F). The CCL-16 mRNA level was increased in HCC-adjacent normal tissues with lymphocytic infiltration, whereas the F2 mRNA level was decreased in the same tissues (Fig. 6G-I). Only the CCL-16 mRNA level had a positive correlation with the TNF- $a$ mRNA level in HCC-adjacent 
Fig. 5 CPAP overexpression positively correlates with inflammation in nontumorous part of HCCs via enhanced STAT3 and NF-KB activation. A, B Human hepatocytes were transfected with GFP and GFP-CPAP, and then WB analysis was then performed using the indicated antibodies (A). The quantitative results are shown. The transcriptional activity of STAT3 and NF-kB was assessed by a reporter assay in GFP and GFP-CPAP-expressing cells (B). C Human hepatocytes transfected with CPAP shRNA, pSUPER-SP1 (SP1) and pSUPER-SP5 (SP5) [29], were collected for WB analysis as described above. pSUPER-NS2 (NS2) is the siRNA vector control. The quantitative results are shown. D, E The mRNA expression levels in hepatocytes transfected with HA-CPAP (D) and CPAP shRNA (SP1 and SP5) (E) were analyzed by RT-qPCR. F-I CPAP $(\mathrm{F}$ and $\mathrm{H})$ and TNF- $a(\mathrm{G}$ and $\mathrm{I}) \mathrm{mRNA}$ expression levels in adjacent normal liver tissues (NT) from HCC patients based on the lymphocytic inflammation status (F-G: normal, $n=20$, inflammation, $n=10)$ and the Ishak fibrosis score $(\mathbf{H}-\mathbf{l}: n=32 ; 0$ : no fibrosis, 1 : portal fibrosis (some), 2: portal fibrosis (most), 3: bridging fibrosis (occasional), 4: bridging fibrosis (marked), 5: incomplete cirrhosis, 6: cirrhosis) in the TCGA-LIHC dataset. The gene expression levels were normalized by FPKM normalization. $\mathbf{J}$, $\mathbf{K}$ Correlation of CPAP and TNF- $a$ mRNA levels in adjacent normal liver tissues (NT) with lymphocytic inflammation from TCGA dataset $(\mathbf{J} ; n=10)$ and the NCKUH HCC cohort (K; $n=38$, Supplementary Table 1) was identified by the Pearson correlation coefficient. The data are presented as the mean \pm SEM values. ${ }^{*} p<0.05$, ${ }^{* *} p<0.01$. Information of the Ishak fibrosis scores (0-6) and adjacent normal tissue inflammation grades (lymphocytic infiltration: slight, $n=20$; mild + severe, $n=10$ ) in the TCGA-LIHC dataset was obtained form the UCSC Xena browser (Supplementary Tables 2 and 3).

normal tissues with lymphocytic infiltration (Fig. 6J-M); no correlation was observed between the mRNA expression levels of MBL2 and TNF- $a$ or F2 and TNF- $a$ (Fig. 6K, L). Studied have reported that the liver-specific chemokine CCL-16 can attract monocytes, lymphocytes and dendritic cells $[18,20]$; in addition, a high concentration of CCL-16 in plasma can modulate inflammatory responses [16]. Our results suggested that CCL-16 could be a biomarker for the early detection of chronic liver inflammation.

Since CPAP plays an important role in inflammatory pathways in human hepatocytes, we investigated the effect of CPAP on CCL-16 expression in human hepatocytes. Overexpression of CPAP increased CCL-16 expression in hepatocytes under both normal culture and TNF-a treatment conditions (Fig. 7A), whereas knockdown of CPAP decreased CCL-16 expression (Fig. 7B). Additionally, GFP-CPAP overexpression increased the secretion of CCL-16 in hepatocytes under normal culture condition (Fig. 7C). The expression of CCL-16 mRNA was positively correlated with that of CPAP mRNA in HCC-adjacent normal tissues with lymphocytic infiltration (Fig. 7D, E). In patients with HCC, serum levels of CCL-16 were positively correlated with the CPAP and TNFa mRNA expression levels in HCC-adjacent normal tissues (Fig. 7F, $\mathrm{G})$. The results from TCGA-LIHC dataset analysis showed that the mRNA expression levels of CPAP and CCL-16 is positively correlated in the nontumoral part of $\mathrm{HCC}$ (Fig. $7 \mathrm{H})$. These results suggested that CPAP can upregulate $\mathrm{CCL}-16$ expression via the TNF-a/NF-KB pathway in inflamed hepatocytes and HCC microenvironment.

\section{DISCUSSION}

Inflammation is tightly associated with cancer development $[40,41]$. Chronic inflammation and the inflammatory microenvironment of hepatocytes are believed to play a vital role in HCC progression [7]. Our results showed that overexpressed CPAP increases the expression of proinflammatory cytokines, including TNF- $a$, IL-6, IL-1 $\beta$, IL-8, and liver-enriched CCL-16, by promoting the activation of two important inflammatory transcriptional factors-STAT3 and NF-KB-to create and maintain a chronic inflammatory microenvironment that facilitates the development of HCC (Fig. 8). In this study, we demonstrated that overexpressed CPAP enhances the inflammatory response by increasing the expression of proinflammatory factors TNFa, IL8, and CCL-16 in hepatocytes. By this finding, we suggest that serum CCL-16 levels might be used as a biomarker for early prediction of HCC onset; people with a high risk of HCC might be monitored by measuring the serum expression level of CCL-16 for early diagnosis.

Our results showed an obvious increase of CPAP protein levels in IL-6- and TNFa-treated human hepatocytes, whereas CPAP mRNA levels are not changed under the same treatment (Fig. 4B). However, in the mouse model, the cpap mRNA level was increased in the livers of DEN-treated mice (Fig. 4A). This differential expression pattern of CPAP mRNA may be due to the different treatments. DEN is widely used to induce hepatocarcinogenesis via the formation of DNA alkylation adducts after bioactivation by hepatic cytochrome P450 (CYP) enzymes [42]. Although our results indicated that DEN treatment enhances the expression of IL- 6 and TNF-a (Fig. 2C), both of which can in turn increase the protein expression level of CPAP as observed in IL-6- and TNF-a-treated human hepatocytes (Fig. 4E, F); however, the mechanisms of DENincreased cpap mRNA expression in the mouse liver remain unclear. One recent report indicated that DEN treatment can increase the expression of the transcription factor Yes-associated protein/transcriptional coactivator with PDZ-binding motif (YAP/ TAZ) [43], an important transcription factor in HCC development [44]. Our previous report indicated that CPAP mRNA levels are increased in HCC [31]; in addition, we showed that the transcription factor CREB can upregulate CPAP expression in HCC [30]. In this study, our results showed that the increased CPAP expression in IL-6- and TNFa-treated human hepatocytes is mediated through SUMO-1 modification (Fig. 4E, F); our previous reports showed that the expression of CPAP mRNA increases during HCC progression [30,31]. Therefore, the increased cpap mRNA level in the livers of DEN-treated mice may be due to unidentified transcription factors activated by DEN. The molecular mechanism of DEN-increased cpap mRNA expression needs further investigation.

In this study, the physiological correlation between CPAP overexpression and liver inflammation in human specimens was analyzed using two different categories, the Ishak fibrosis score and the lymphocytic infiltration level [38]. CPAP expression was not correlated with the Ishak fibrosis score in either the TCGA database or the NCKUH cohort, but was positively associated with the lymphocytic infiltration level (Fig. 5F-I). Although the CPAP Tg mice exhibited increased liver inflammation and some developed HCC (Fig. 1), no fibrosis was observed. In addition, in human specimens, the expression of CCL-16, which was increased upon IL-6 and TNF-a treatment (Fig. 6A), was positively associated with the inflammation level but not the Ishak fibrosis score (Fig. 6D-G). The positive correlations between CPAP and TNF-a (Fig. 5J), TNF-a and CCL-16 (Figs. 6J, M and 7G), and CPAP and CCL-16 (Fig. 7D-F) suggested that CPAP overexpression in hepatocytes is closely related to liver inflammation. Injured liver cells can release factors to attract immune cells for infiltration, and these immune cells then secrete chemokines to create an inflammatory microenvironment and further increase inflammatory cell infiltration [45]. Because there is no active $\mathrm{Ccl}-16$ in mice $[46,47]$, we therefore cannot test the effects of $\mathrm{Ccl}-16$ in CPAP Tg mice. However, by using human hepatocytes and clinical analysis, our results provided evidence to propose an additional liver inflammatory mechanism acting by overexpressed CPAP. We propose that overexpression of CPAP increases the level of CCL-16 to interact with its receptor CCR2, which is located in Kupffer cells and other recruited macrophages; these macrophages then secrete cytokines to attract more inflammatory cell infiltrating, in turn creating 
(A)

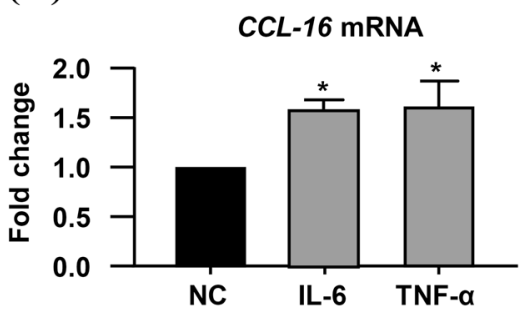

(D)

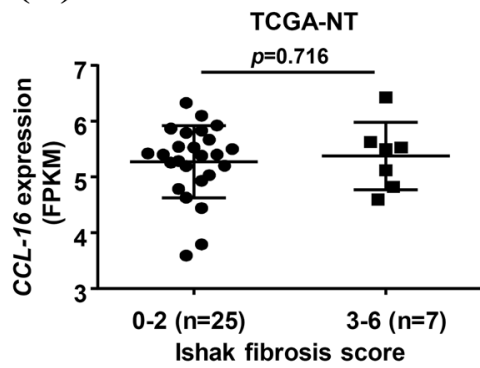

(G)

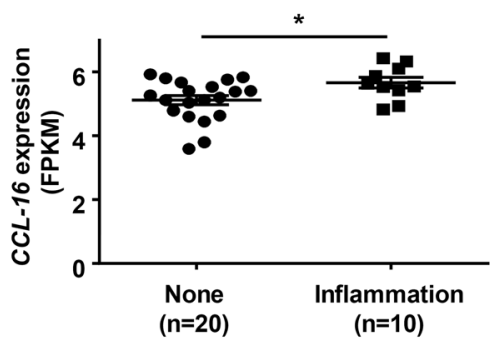

(J)

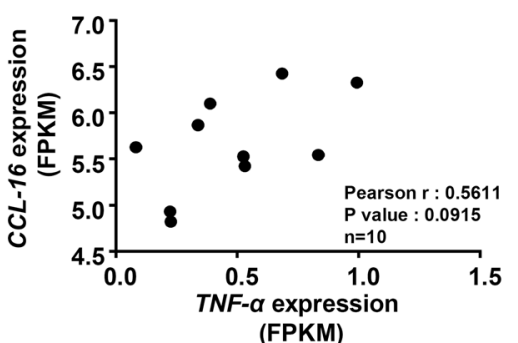

(M)

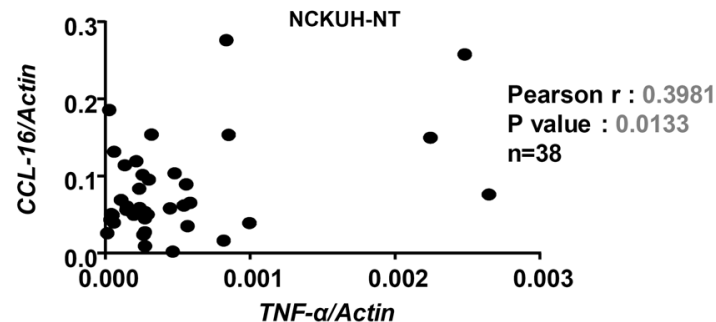

Fig. 6 Liver-secreted CCL-16 is positively correlated with TNF-a expression. A-C The expression levels of CCL-16, MBL2, and F2 mRNAs in human hepatocytes treated without (NC) or with IL-6 or TNF- $\alpha$ were determined by RT-qPCR. D-I The expression levels of CCL-16, MBL2, and F2 mRNAs in adjacent normal liver tissues (NT) of HCC patients from the TCGA-LIHC dataset with different Ishak fibrosis scores (D-F) and lymphocytic inflammation statuses (G-I) are shown. J-L Correlations between CCL-16, MBL2, and F2 mRNA levels and the TNF- $a$ mRNA level in adjacent normal liver tissues with lymphocytic inflammation $(n=10)$ from the TCGA-LIHC dataset were identified by the Pearson correlation coefficients. M The correlation between TNF- $a$ and CCL-16 mRNA expression levels in the adjacent normal liver tissues of HCC patients $(n=38)$ from the NCKUH cohort was identified by the Pearson correlation coefficient. ${ }^{*} p<0.05,{ }^{* *} p<0.01$. 
(A)
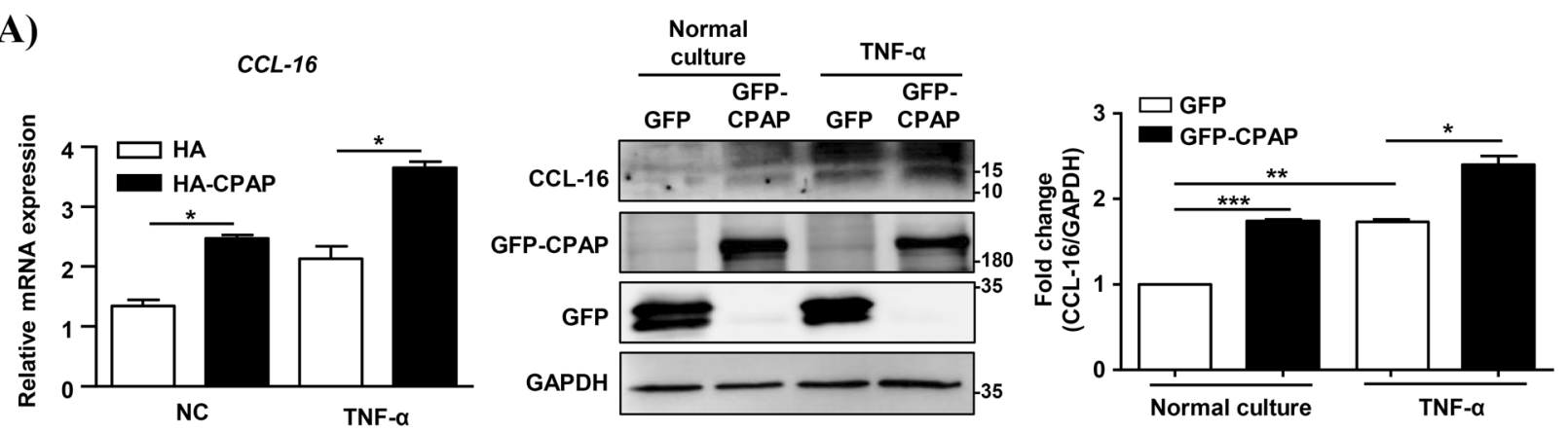

(B)
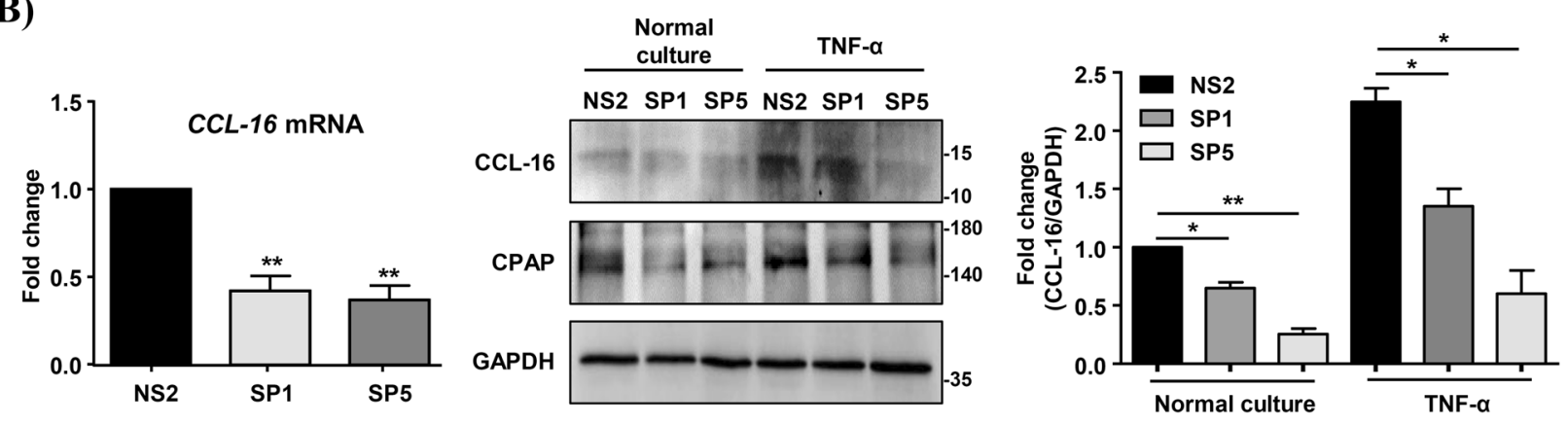

(C)

(D)

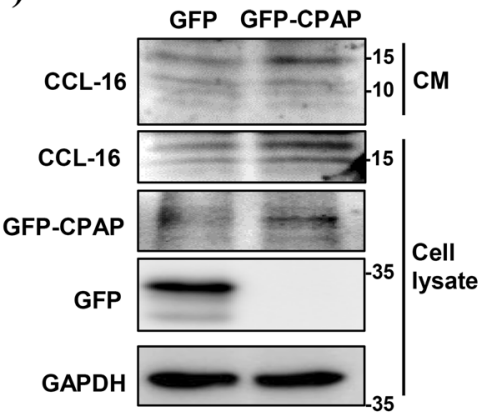

(F)

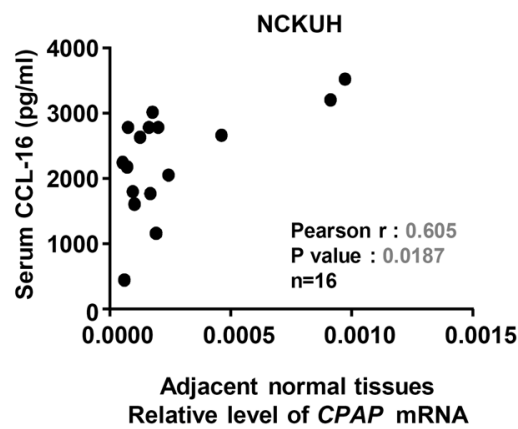

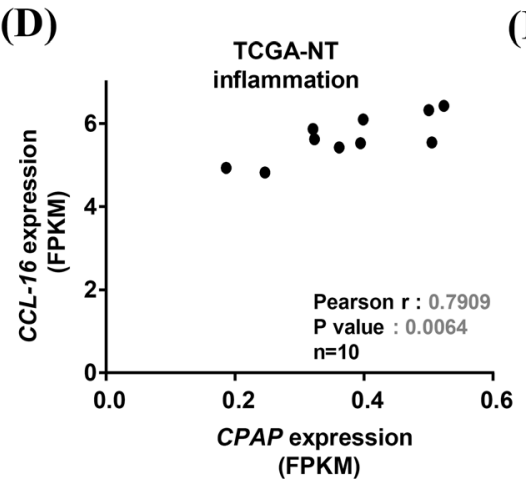

(E)

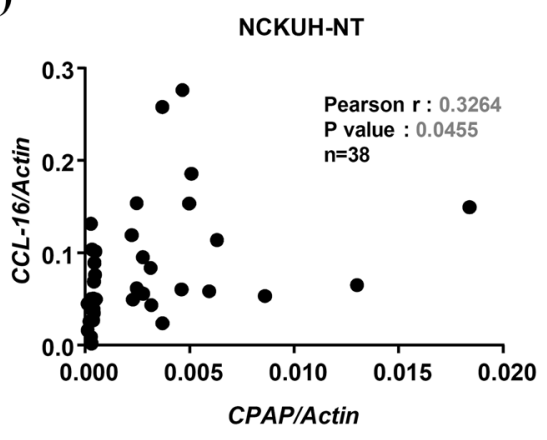

(G)

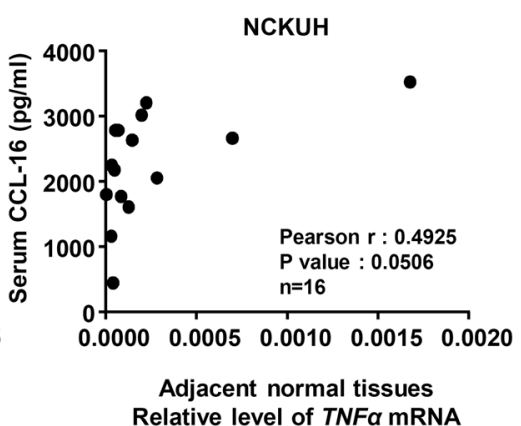

(H)

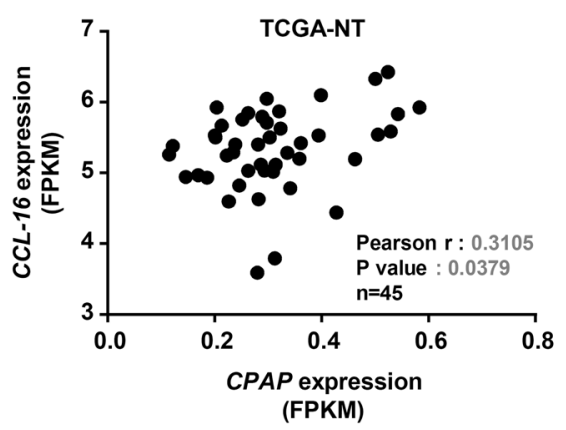

and maintaining an inflammatory microenvironment in liver tissues. The increased expression of CCL-16 could be used as a biomarker for early prediction of HCC development, and this is not correlated with liver fibrosis. More investigation is needed to further confirm the importance of CCL-16 in inflammationinduced hepatocarcinogenesis.

Currently, HCC therapy remains unsatisfactory. The response to small molecule inhibitors, such as sorafenib, regorafenib, lenvatinib, and the 5-fluorouracil, leucovorin, and oxaliplatin (FOLFOX4) regimen recently recommended by the FDA, is limited and accompanied by a high recurrence rate [48]. Recently, immune checkpoint blockade has provided an effective and promising therapeutic strategy for cancer [49]; the considerable anticancer effect of immune checkpoint inhibitors has been approved in a variety of cancers, including HCC [48]. Immunotherapy will undoubtedly become a promising therapeutic strategy for HCC. CCL-16 has been reported to be overexpressed in human hepatocytes and HepG2 cells [16], and the current studies suggest 
Fig. 7 CPAP promotes inflammatory cell infiltration by increasing TNF- $\boldsymbol{a} / \mathrm{CCL}-16$ signaling. A Human hepatocytes were transfected with HA and HA-CPAP (left), or with GFP and GFP-CPAP (right), and the expression of CCL-16 was then evaluated by RT-qPCR analysis (left) and WB analysis (right) under normal culture (NC) condition or after treatment with $10 \mathrm{ng} / \mathrm{ml}$ TNF- $\alpha$ for $24 \mathrm{~h}$. B Human hepatocytes transfected with CPAP shRNA (SP1 and SP5) were collected to evaluate the expression of CCL-16 as described above. pSUPER-NS2 (NS2) is the siRNA vector control. The protein expression levels of CCL-16 are displayed as ratios and are shown below the blot image. C Conditioned media from GFPand GFP-CPAP-transfected hepatocytes were collected to detect secreted CCL-16 by WB analysis. Total cell lysates were collected to determine the expression of GFP and GFP-CPAP. GAPDH was used as the loading control. The data are presented as the mean \pm SEM values. ${ }^{*} p<0.05,{ }^{* *} p$ $<0.01$. D, E The mRNA expression levels of CCL-16 and CPAP in adjacent normal liver tissues with lymphocytic inflammation were measured to determine their correlation by Pearson correlation analysis. TCGA-LICH dataset $(\mathbf{D}, n=10): \mathrm{R}=0.7909, p=0.0064 ; \mathrm{NCKUH}$ cohort $(\mathbf{E}, \mathrm{n}-38): \mathrm{R}=$ $0.3264, p=0.0455$. F-G The levels of secreted CCL-16 protein, CPAP mRNA and TNF-a mRNA were determined in serum and adjacent normal liver tissues from the NCKUH cohort $(n=16)$. The correlations between CCL-16 mRNA and CPAP mRNA levels (F) and between CCL-16 mRNA and TNF- $a$ mRNA levels (G) were assessed by the Pearson correlation coefficients. $\mathbf{H}$ The correlation between CCL-16 mRNA and CPAP mRNA in the nontumoral part of HCC from the NCKUH cohort $(n=43)$.

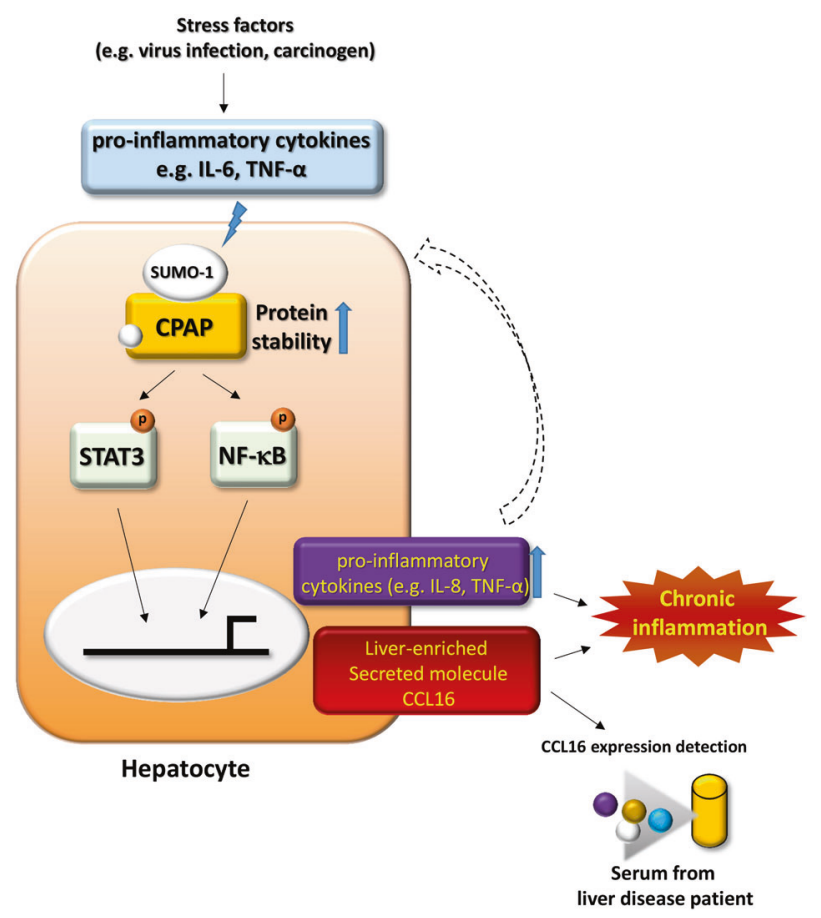

Fig. 8 CPAP promotes and maintains liver inflammation by increasing the secretion of inflammatory cytokines via STAT3 and NF-KB. Upon viral infection or hepatic injury, human hepatocytes are under the stimulation of inflammatory cytokines, which increases CPAP protein stability through SUMO-1 modification. SUMO-1-modified CPAP enhances the expression of inflammatory cytokines, including TNF- $\alpha, \mathrm{IL}-8$, and CCL-16, by promoting the transcriptional activities of STAT3 and NF- $\mathrm{KB}$. This CPAP-mediated enhancement of cytokine expression contributes to the chronic inflammatory microenvironment surrounding hepatocytes.

a potential role of overexpressed CCL-16 in liver inflammation which is important for the development of hepatitis and HCC. CCL-16 overexpression was positively correlated with liver inflammation (Fig. 6G), and the expression of CCL-16 was increased in inflamed hepatocytes in CPAP-overexpressing cells via enhancement of STAT3 and NF-KB activity (Figs. 6A and 7). Blockade of the pathways involved in CPAP-mediated CCL-16 expression or inhibition of the interaction between CCL-16 and its receptors may provide a novel strategy in hepatitis and HCC therapies. However, the anticancer effects of STAT3 and NF-KB inhibitors are limited, and these drugs may produce several side effects after long-term treatment $[50,51]$; therefore, the usage of anti-CCL-16 antibodies to block the interaction of CCL-16 with its receptors may become an attractive strategy to block the interaction between CCL-16 and its receptors in treating hepatitis, preventing liver inflammation and HCC development.

\section{MATERIALS AND METHODS Establishment of Tg mice with liver-specific expression of CPAP}

The CPAP gene was cloned by the Sall and Pmel in pAlb-In-pA-HS4 [32], under the control of a hepatocyte-specific albumin promoter. C57BL/6 J mice were used to generate CPAP Tg mice by pronucleus microinjection into fertilized eggs. The tails of individual 7-day-old mice were cut, and genomic DNA was isolated with a Mouse Direct PCR Kit (Biotool, Houston, TX, USA). The genotype of Tg mice was determined by PCR with the indicated primer pairs (please see Supplementary Fig. S1 and Supplementary Table 4). PCR amplification was performed under the following conditions: predenaturation at $94^{\circ} \mathrm{C}$ for $5 \mathrm{~min} ; 35$ cycles of denaturation at $94^{\circ} \mathrm{C}$ for $30 \mathrm{sec}$, annealing at $58^{\circ} \mathrm{C}$ for $30 \mathrm{sec}$, and extension at $72^{\circ} \mathrm{C}$ for $30 \mathrm{sec}$; a final extension step at $72^{\circ} \mathrm{C}$ for $5 \mathrm{~min}$; and holding at $4{ }^{\circ} \mathrm{C}$. All mice were bred in a specific pathogen-free room. $H B x$ Tg mice [32] were used to generate $C P A P / H B x$ double-transgenic $(\mathrm{CH} \mathrm{Tg})$ mice. The animal experiments were approved by the Institutional Animal Care and Use Committee (IACUC104056) at National Cheng-Kung University.

\section{Determination of serum ALT/GPT activity}

Mouse serum was collected to determine the ALT level with FUJ DRI-CHEM 4000i chemistry analyzers (FUJIFILM Corporation, Tokyo, Japan).

\section{Establishment of the DEN-induced acute hepatic injury and HCC mouse models}

To establish the short-term DEN-induced acute hepatic injury model, twoweek-old mice were injected intraperitoneally (IP) with $100 \mathrm{mg} / \mathrm{kg}$ DEN (N0756, Sigma-Aldrich, St. Louis, MO, USA) for 0, 4, 24 and $48 \mathrm{~h}$; mice were sacrificed $48 \mathrm{~h}$ after injection. To establish the long-term DEN-induced HCC model, 15-day-old mice were injected IP with $25 \mathrm{mg} / \mathrm{kg}$ DEN; then the hepatic injury and hepatic tumorigenesis were monitored by ALT level measurement and ultrasound begining 5 months after DEN injection. Mice were sacrificed 9 and 11 months after DEN injection.

\section{Cell culture, transfection and reagents}

Human hepatocytes (HHs) were purchased from ScienCell (HHs, Cat\#5200, ScienCell Research Laboratories, Carlsbad, CA, USA), and cultured according to the manufacturer's instructions. In brief, HHs were cultured in hepatocyte medium (HM, Cat\#5201, ScienCell) supplemented with hepatocyte growth supplement (HGS, Cat \#5252, ScienCell), 5\% fetal bovine serum (FBS, Cat \#0025, ScienCell) and 100 unit $/ \mathrm{ml}$ penicillin/ streptomycin (P/S, Cat\#0503, ScienCell). HHs were transfected with plasmids as indicated in the text using PolyJet ${ }^{\mathrm{TM}}$ (SL100688, SignaGen, Rockville, MD, USA). Cells were treated with $25 \mathrm{ng} / \mathrm{ml}$ human IL-6 (GF338, Millipore, Billerica, MA, USA) or $10 \mathrm{ng} / \mathrm{ml}$ human TNF-a (GF314, Millipore, Billerica, MA, USA) after $18-20 \mathrm{~h}$ starvation in serum-free medium. All experiments were performed by three separate batches of $\mathrm{HH}$. Cells were kept in mycoplasma-free by checking the mycoplasma contamination status once per month.

\section{Western blot (WB) analysis}

Total cell lysates were harvested using RIPA buffer $(50 \mathrm{mM}$ Tris- $\mathrm{HCl}(\mathrm{pH} 7.4)$, $150 \mathrm{mM} \mathrm{NaCl}, 1 \mathrm{mM}$ EDTA, $1 \%$ Nonidet P-40, and $0.25 \%$ sodium deoxycholate) with protease inhibitor cocktails (Cat\#P8340, Sigma-Aldrich, St. Louis, MO, USA). The antibodies used in this study are described below: anti-GFP (JL-8, Clontech, Mountain View, CA, USA), anti-CPAP (ab221134, 
Abcam, Danvers, MA, USA), anti-STAT3 (9139, Cell signaling, Danvers, MA, USA), anti-phospho-STAT3/Y705 (9145, Cell Signaling), anti-phospho-p65 (3036, Cell Signaling), anti-p65 (8242, Cell Signaling), anti-cleaved caspase3 (9661, Cell Signaling), anti-GAPDH (sc32233, Santa Cruz, Dallas, TX) and anti-a-tubulin (DM1A, T6299, Sigma-Aldrich).

\section{RNA extraction, reverse transcription (RT) and quantitative PCR (qPCR)}

Total RNA was extracted and purified as previously described [29]. RNA from tissues and cells was isolated using TRIsure ${ }^{\mathrm{T} M}$ reagent following the manufacturer's instructions (BIO-38033, Bioline, London, UK). One microgram of RNA was reverse-transcribed with a High-Capacity CDNA Reverse Transcription Kit (Applied Biosystems) according to the manufacturer's instructions. SYBR ${ }^{\circ}$ Green Supermix (170-8882, BIO-RAD, Hercules, CA, USA) was used for qPCR. Primer information is listed in Supplementary Table 4.

\section{STAT3 and NF-KB reporter activity assay}

Cells were cotransfected with the STAT3 or NF-KB-driven reporter plasmid and the Renilla luciferase reporter plasmid using PolyJet ${ }^{\mathrm{TM}}$. The transcriptional activity of STAT3 or NF-KB was measured using a Dual-Luciferase Reporter kit (Promega, Madison, WI, USA) according to the manufacturer's instructions.

\section{In situ proximity ligation assay (PLA)}

Cells seeded on a sterile $12-\mathrm{mm}$ coverslip were treated with $25 \mathrm{ng} / \mathrm{ml} \mathrm{IL-6}$ or $10 \mathrm{ng} / \mathrm{ml} \mathrm{TNF-a} \mathrm{for} 4 \mathrm{~h}$ and were then fixed with ice-cold EtOH/acetone ( v/v 1:1) at $-20^{\circ} \mathrm{C}$ for $20 \mathrm{~min}$. In situ PLA was performed as previously described [29] (Olink Bioscience, Uppsala, Sweden). Two primary antibodies derived from different species were used to recognize SUMO1 (33-2400, Thermo Fisher Scientific, Inc., Waltham, MA, USA) and CPAP. The antibodies used in this study were anti-SUMO1 monoclonal antibody and anti-CPAP polyclonal antibody [52]. The bright red fluorescent puncta were amplified when a direct protein-protein interaction was present and detected using a fluorescence microscope (BX51, Olympus, Japan).

\section{HCC patient specimens}

HCC specimens from National Cheng Kung University Hospital (NCKUH) were collected for this study with the approval of the Institutional Review Board (IRB), NCKUH, Tainan, Taiwan (B-ER-104-245). Studies involving clinical specimens were conducted in accordance with the 1975 Declaration of Helsinki, as revised in 1983.

\section{Bioinformatic and statistical analyses}

Information on adjacent normal tissues with lymphocytic inflammation status and Ishak fibrosis scores, as well as mRNA expression data (normalized read counts of samples as FPKM values), was obtained from the UCSC Xena Browser (https://xenabrowser.net/). Parametric unpaired and paired two-tailed Student's $t$ tests were used to evaluate the differences between the control and experimental groups. Pearson correlation analysis was applied to analyze genes expression correlations. Data are presented as the mean \pm SEM values. ${ }^{*} p<0.05$; ${ }^{* *} p<0.01$; and ${ }^{* * *} p<0.001$.

\section{DATA AVAILABILITY}

The authors declare that all data supporting the findings of this study are available within the article.

\section{REFERENCES}

1. Yang JD, Hainaut P, Gores GJ, Amadou A, Plymoth A, Roberts LR. A global view of hepatocellular carcinoma: trends, risk, prevention and management. Nat Rev Gastroenterol Hepatol. 2019;16:589-604.

2. Fattovich G, Stroffolini T, Zagni I, Donato F. Hepatocellular carcinoma in cirrhosis: incidence and risk factors. Gastroenterology 2004;127:S35-50.

3. Medzhitov R. Origin and physiological roles of inflammation. Nature 2008;454:428-35.

4. Yu LX, Ling Y, Wang HY. Role of nonresolving inflammation in hepatocellular carcinoma development and progression. NPJ Precis Oncol. 2018;2:6.

5. Nathan C, Ding A. Nonresolving inflammation. Cell 2010;140:871-82.
6. Mantovani A, Allavena P, Sica A, Balkwill F. Cancer-related inflammation. Nature 2008;454:436-44.

7. Refolo MG, Messa C, Guerra V, Carr BI, D'Alessandro R. Inflammatory mechanisms of HCC development. Cancers. 2020;12:641-63.

8. Hatano K, Fujita K, Nonomura N. Application of anti-inflammatory agents in prostate cancer. J Clin Med. 2020;9:2680-706.

9. He G, Karin M. NF-kappaB and STAT3 - key players in liver inflammation and cancer. Cell Res. 2011;21:159-68.

10. Taniguchi K, Karin M. NF-kappaB, inflammation, immunity and cancer: coming of age. Nat Rev Immunol. 2018;18:309-24.

11. Lee C, Cheung ST. STAT3: an emerging therapeutic target for hepatocellular carcinoma. Cancers. 2019;11:1646-65.

12. Xia Y, Shen S, Verma IM. NF-kappaB, an active player in human cancers. Cancer Immunol Res. 2014;2:823-30.

13. Shoudai $K$, Hieshima K, Fukuda S, lio M, Miura R, Imai T, et al. Isolation of cDNA encoding a novel human CC chemokine NCC-4/LEC. Biochim Biophys Acta. 1998;1396:273-7.

14. Zhuo JY, Lu D, Lin ZY, Cen BN, Wei XY, Xie HY, et al. CC motif chemokine ligand 16 inhibits the progression of liver cirrhosis via inactivating hepatic stellate cells. Hepatobiliary Pancreat Dis Int. 2020;19:440-8.

15. Howard OM, Dong HF, Shirakawa AK, Oppenheim JJ. LEC induces chemotaxis and adhesion by interacting with CCR1 and CCR8. Blood 2000;96:840-5.

16. Nomiyama H, Hieshima K, Nakayama T, Sakaguchi T, Fujisawa R, Tanase S, et al. Human CC chemokine liver-expressed chemokine/CCL16 is a functional ligand for CCR1, CCR2 and CCR5, and constitutively expressed by hepatocytes. Int Immunol. 2001;13:1021-9.

17. Korbecki J, Kojder K, Siminska D, Bohatyrewicz R, Gutowska I, Chlubek D, et al. CC chemokines in a tumor: a review of pro-cancer and anti-cancer properties of the ligands of receptors CCR1, CCR2, CCR3, and CCR4. Int J Mol Sci. 2020;21:8412-40.

18. Youn BS, Zhang S, Broxmeyer HE, Antol K, Fraser MJ Jr., Hangoc G, et al. Isolation and characterization of LMC, a novel lymphocyte and monocyte chemoattractant human CC chemokine, with myelosuppressive activity. Biochem Biophys Res Commun. 1998;247:217-22.

19. Nakayama T, Kato $Y$, Hieshima $K$, Nagakubo D, Kunori $Y$, Fujisawa $T$, et al. Liverexpressed chemokine/CC chemokine ligand 16 attracts eosinophils by interacting with histamine H4 receptor. J Immunol. 2004;173:2078-83.

20. Cappello P, Fraone T, Barberis L, Costa C, Hirsch E, Elia AR, et al. CC-chemokine ligand 16 induces a novel maturation program in human immature monocytederived dendritic cells. J Immunol. 2006;177:6143-51.

21. Guo J, Cheng Y. MicroRNA-1247 inhibits lipopolysaccharides-induced acute pneumonia in A549 cells via targeting CC chemokine ligand 16. Biomed Pharmacother. 2018;104:60-8.

22. Cappello P, Caorsi C, Bosticardo M, De Angelis S, Novelli F, Forni G, et al. CCL16/ LEC powerfully triggers effector and antigen-presenting functions of macrophages and enhances T cell cytotoxicity. J Leukoc Biol. 2004;75:135-42.

23. Pannellini T, lezzi $M, D i$ Carlo E, Eleuterio E, Coletti $A$, Modesti $A$, et al. The expression of LEC/CCL16, a powerful inflammatory chemokine, is upregulated in ulcerative colitis. Int J Immunopathol Pharm. 2004;17:171-80.

24. Del Valle-Pinero AY, Martino AC, Taylor TJ, Majors BL, Patel NS, Heitkemper MM, et al. Pro-inflammatory chemokine C-C motif ligand 16 (CCL-16) dysregulation in irritable bowel syndrome (IBS): a pilot study. Neurogastroenterol Motil. 2011;23:1092-7.

25. Hayatbakhsh MM, Gowhari Shabgah A, Pishgouyi S, Tavakol Afshari J, Zeidabadi $H$, Mohammadi $M$. The serum levels of CCL2 and CCL16 expression in patients with irritable bowel syndrome. Rep Biochem Mol Biol. 2019;8:9-14.

26. Strasly M, Doronzo G, Cappello P, Valdembri D, Arese M, Mitola S, et al. CCL16 activates an angiogenic program in vascular endothelial cells. Blood 2004;103:40-9.

27. Schmidt TI, Kleylein-Sohn J, Westendorf J, Le Clech M, Lavoie SB, Stierhof YD, et al. Control of centriole length by CPAP and CP110. Curr Biol. 2009;19:1005-11.

28. Tang CJ, Fu RH, Wu KS, Hsu WB, Tang TK. CPAP is a cell-cycle regulated protein that controls centriole length. Nat Cell Biol. 2009;11:825-31.

29. Chen RY, Yen CJ, Liu YW, Guo CG, Weng CY, Lai $C H$, et al. CPAP promotes angiogenesis and metastasis by enhancing STAT3 activity. Cell Death Differ. 2020;27:1259-73.

30. Yen CJ, Yang ST, Chen RY, Huang W, Chayama K, Lee MH, et al. Hepatitis B virus X protein $(\mathrm{HBx})$ enhances centrosomal P4.1-associated protein (CPAP) expression to promote hepatocarcinogenesis. J Biomed Sci. 2019;26:44.

31. Yang ST, Yen CJ, Lai CH, Lin YJ, Chang KC, Lee JC, et al. SUMOylated CPAP is required for IKK-mediated NF-kappaB activation and enhances $\mathrm{HBx}$-induced NFkappaB signaling in HCC. J Hepatol. 2013;58:1157-64.

32. Wu BK, Li CC, Chen HJ, Chang JL, Jeng KS, Chou CK, et al. Blocking of G1/S transition and cell death in the regenerating liver of Hepatitis $B$ virus $X$ protein transgenic mice. Biochem Biophys Res Commun. 2006;340:916-28. 
33. Connor F, Rayner TF, Aitken SJ, Feig C, Lukk M, Santoyo-Lopez J, et al. Mutational landscape of a chemically-induced mouse model of liver cancer. J Hepatol. 2018;69:840-50.

34. Yu Y, Gong R, Mu Y, Chen Y, Zhu C, Sun Z, et al. Hepatitis B virus induces a novel inflammation network involving three inflammatory factors, IL-29, IL-8, and cyclooxygenase-2. J Immunol. 2011;187:4844-60.

35. Stein S, Lemos V, Xu P, Demagny H, Wang X, Ryu D, et al. Impaired SUMOylation of nuclear receptor LRH-1 promotes nonalcoholic fatty liver disease. J Clin Invest. 2017;127:583-92.

36. Lee-Law PY, Olaizola P, Caballero-Camino FJ, Izquierdo-Sanchez L, Rodrigues PM, Santos-Laso A, et al. Targeting UBC9-mediated protein hyper-SUMOylation in cystic cholangiocytes halts polycystic liver disease in experimental models. J Hepatol. 2020;74:394-406.

37. Zeng M, Liu W, Hu Y, Fu N. Sumoylation in liver disease. Clin Chim Acta. 2020;510:347-53.

38. Goodman ZD. Grading and staging systems for inflammation and fibrosis in chronic liver diseases. J Hepatol. 2007:47:598-607.

39. Franko A, Hartwig S, Kotzka J, Ruoss M, Nussler AK, Konigsrainer A, et al. Identification of the secreted proteins originated from primary human hepatocytes and HepG2 cells. Nutrients. 2019;11:1795-816.

40. Murata M. Inflammation and cancer. Environ Health Prev Med. 2018;23:50.

41. Singh N, Baby D, Rajguru JP, Patil PB, Thakkannavar SS, Pujari VB. Inflammation and cancer. Ann Afr Med. 2019;18:121-6.

42. Verna L, Whysner J, Williams GM. N-nitrosodiethylamine mechanistic data and risk assessment: bioactivation, DNA-adduct formation, mutagenicity, and tumor initiation. Pharm Ther. 1996;71:57-81.

43. Zhu H, Yan F, Yuan T, Qian M, Zhou T, Dai X, et al. USP10 promotes proliferation of hepatocellular carcinoma by deubiquitinating and stabilizing YAP/TAZ. Cancer Res. 2020;80:2204-16

44. Zhang S, Zhou D. Role of the transcriptional coactivators YAP/TAZ in liver cancer. Curr Opin cell Biol. 2019;61:64-71.

45. Koyama $Y$, Brenner DA. Liver inflammation and fibrosis. J Clin Invest 2017;127:55-64.

46. Fukuda S, Hanano Y, lio M, Miura R, Yoshie O, Nomiyama H. Genomic organization of the genes for human and mouse CC chemokine LEC. DNA Cell Biol. 1999;18:275-83.

47. Shibata K, Nomiyama H, Yoshie O, Tanase S. Genome diversification mechanism of rodent and Lagomorpha chemokine genes. Biomed Res Int. 2013;2013:856265.

48. Liu X, Qin S. Immune checkpoint inhibitors in hepatocellular carcinoma: opportunities and challenges. oncologist. 2019;24:S3-S10.

49. Li B, Chan HL, Chen P. Immune checkpoint inhibitors: basics and challenges. Curr medicinal Chem. 2019:26:3009-25.

50. Zhu Z, Zhong S, Shen Z. Targeting the inflammatory pathways to enhance chemotherapy of cancer. Cancer Biol Ther. 2011;12:95-105

51. Gupta SC, Kunnumakkara AB, Aggarwal S, Aggarwal BB. Inflammation, a doubleedge sword for cancer and other age-related diseases. Front Immunol. 2018;9:2160.

52. Hung LY, Tang CJ, Tang TK. Protein 4.1 R-135 interacts with a novel centrosomal protein (CPAP) which is associated with the gamma-tubulin complex. Mol Cell Biol. 2000;20:7813-25

\section{ACKNOWLEDGEMENTS}

The authors thank Dr. Ming-Derg Lai for helpful comments and discussion, and Nature Publishing Group language editing and a native speaker Mr. Chris Herbert for help with English editing. We thank the Laboratory Animal Center, College of
Medicine, National Cheng Kung University and Taiwan Animal Consortium for the technical support in generation of transgenic mice. This work was supported by grants MOST104-2320-B-006-020-MY3, MOST 107-2314-B-006-048, MOST108-2320-B006-017, and MOST109-2320-B-006-055 from Ministry of Science and Technology (Taipei, Taiwan), and National Cheng Kung University Hospital (NCKUH-10902017 and NCKUH-11002045) (Tainan, Taiwan). The authors declare no competing financial interests.

\section{AUTHOR CONTRIBUTIONS}

LYH, RYC and CJY conducted and designed the experiments and wrote the manuscript; RYC, JMW, TFT, YCH, YWL, HWT and MHL generated the data; $\mathrm{LYH}, \mathrm{RYC}$ CJY and YJL analyzed the clinical data; LYH, RYC, CJY, YJL, YWL and HWT analyzed the data.

\section{ETHICS}

This study was conducted in accordance with the 1975 Declaration of Helsinki, as revised in 1983 with the approval of the Institutional Review Board (IRB), NCKUH, Tainan, Taiwan (B-ER-104-245).

\section{COMPETING INTERESTS}

The authors declare no competing interests.

\section{ADDITIONAL INFORMATION}

Supplementary information The online version contains supplementary material available at https://doi.org/10.1038/s41419-021-04295-2.

Correspondence and requests for materials should be addressed to Liang-Yi Hung.

Reprints and permission information is available at http://www.nature.com/ reprints

Publisher's note Springer Nature remains neutral with regard to jurisdictional claims in published maps and institutional affiliations.

Open Access This article is licensed under a Creative Common cc) Attribution 4.0 International License, which permits use, sharing, adaptation, distribution and reproduction in any medium or format, as long as you give appropriate credit to the original author(s) and the source, provide a link to the Creative Commons license, and indicate if changes were made. The images or other third party material in this article are included in the article's Creative Commons license, unless indicated otherwise in a credit line to the material. If material is not included in the article's Creative Commons license and your intended use is not permitted by statutory regulation or exceeds the permitted use, you will need to obtain permission directly from the copyright holder. To view a copy of this license, visit http://creativecommons. org/licenses/by/4.0/.

(c) The Author(s) 2021 